\title{
Role of Sulfonylurea Receptor 1 and Glibenclamide in Traumatic Brain Injury: A Review of the Evidence
}

\author{
Ruchira M. Jha ${ }^{1, *(\mathbb{D})}$, Josh Bell ${ }^{2}$, Giuseppe Citerio ${ }^{3,4}{ }^{\mathbb{D}}$, J. Claude Hemphill ${ }^{5}$, \\ W. Taylor Kimberly ${ }^{6}$, Raj K. Narayan ${ }^{7}$, Juan Sahuquillo ${ }^{8,9,10}$, Kevin N. Sheth ${ }^{11}$ \\ and J. Marc Simard 12,*(D) \\ 1 Departments of Critical Care Medicine, Neurology, Neurological Surgery, Clinical and Translational Science \\ Institute, University of Pittsburgh, Pittsburgh, PA 15201, USA \\ 2 Biogen, Cambridge, MA 02142, USA; josh.bell@biogen.com \\ 3 School of Medicine and Surgery, University of Milan-Bicocca, 20121 Milan, Italy; giuseppe.citerio@unimib.it \\ 4 Anaesthesia and Intensive Care, San Gerardo and Desio Hospitals, ASST-Monza, 20900 Monza, Italy \\ 5 Department of Neurology, University of California, San Francisco, CA 94110, USA; \\ claude.hemphill@ucsf.edu \\ 6 Division of Neurocritical Care and Center for Genomic Medicine, Department of Neurology, Massachusetts \\ General Hospital, Boston, MA 02108, USA; WTKIMBERLY@mgh.harvard.edu \\ 7 Department of Neurosurgery, North Shore University Hospital, Donald and Barbara Zucker School of \\ Medicine at Hofstra/Northwell, Manhasset, NY 11030, USA; RNarayan@northwell.edu \\ 8 Neurotrauma and Neurosurgery Research Unit (UNINN), Vall d'Hebron Research Institute (VHIR), 08001 \\ Barcelona, Spain; sahuquillo.juan@gmail.com \\ 9 Department of Neurosurgery, Universitat Autònoma de Barcelona (UAB), 08001 Barcelona, Spain \\ 10 Department of Neurosurgery, Vall d'Hebron University Hospital, 08001 Barcelona, Spain \\ 11 Division of Neurocritical Care and Emergency Neurology, Department of Neurology, Yale University School \\ of Medicine, New Haven, CT 06501, USA; kevin.sheth@yale.edu \\ 12 Department of Neurosurgery, University of Maryland School of Medicine, Baltimore, MD 21201, USA \\ * Correspondence: ruchirajha@gmail.com (R.M.J.); MSimard@som.umaryland.edu (J.M.S.)
}

Received: 14 December 2019; Accepted: 3 January 2020; Published: 9 January 2020

\begin{abstract}
Cerebral edema and contusion expansion are major determinants of morbidity and mortality after TBI. Current treatment options are reactive, suboptimal and associated with significant side effects. First discovered in models of focal cerebral ischemia, there is increasing evidence that the sulfonylurea receptor 1 (SUR1) - Transient receptor potential melastatin 4 (TRPM4) channel plays a key role in these critical secondary injury processes after TBI. Targeted SUR1-TRPM4 channel inhibition with glibenclamide has been shown to reduce edema and progression of hemorrhage, particularly in preclinical models of contusional TBI. Results from small clinical trials evaluating glibenclamide in TBI have been encouraging. A Phase-2 study evaluating the safety and efficacy of intravenous glibenclamide (BIIB093) in brain contusion is actively enrolling subjects. In this comprehensive narrative review, we summarize the molecular basis of SUR1-TRPM4 related pathology and discuss TBI-specific expression patterns, biomarker potential, genetic variation, preclinical experiments, and clinical studies evaluating the utility of treatment with glibenclamide in this disease.
\end{abstract}

Keywords: SUR1 (Sulfonylurea receptor 1); TRPM4 (transient receptor potential melastatin 4); TBI (traumatic brain injury); cerebral edema; contusion expansion; glibenclamide; glyburide; ASTRAL

\section{Introduction}

The public health impact of traumatic brain injury (TBI) on death and disability is immense. With more than 50 million cases annually, TBI is projected to remain the leading global cause of 
neurological disability until 2030, surpassing Alzheimer's disease and cerebrovascular disorders [1]. Although characteristics of the primary injury are generally considered non-modifiable, reducing the impact of secondary injury has the potential to substantially improve outcomes after TBI. Existing multivariable TBI clinical outcome prediction models from large patient populations such as IMPACT (International Mission for Prognosis and Clinical Trial design in TBI) explain $~ 35 \%$ of outcome variability $[2,3]$. These models predominantly utilize non-modifiable injury characteristics (demographics, severity, motor score, pupillary reactivity with some added value from admission computed tomography (CT), laboratory values and second insults). Thus, more than $50 \%$ of TBI outcome variability may be related to host-response and secondary injury processes, providing tremendous opportunity for targeted intervention.

Cerebral edema and contusion expansion are key secondary injury contributors to post-traumatic morbidity and mortality and for decades have commanded a significant proportion of neurosurgical and neurocritical care resources [4-28]. There is also evidence that traumatic microbleeds (previously considered markers of axonal injury) may represent vascular injury with perivascular iron laden macrophages tracking a network of injured vessels [29] —yet another permutation of vascular secondary injury that has unfavorable functional consequences and that may respond to targeted therapy [29-32]. Cerebral edema has been noted to occur in up to $60 \%$ of TBI patients with mass lesions and $~ 15 \%$ with initially 'negative' CT scans [13,33-35]. Contusion expansion, an extreme manifestation of vasogenic edema and blood brain barrier (BBB) breakdown, occurs in approximately $50 \%$ of cases [4-9]. Cerebral edema is a major cause of intracranial hypertension; these concepts are related via the Monro-Kellie doctrine, autoregulation, and pressure-volume relationships such as intracranial compliance and elastance [14]. While intracranial pressure (ICP) has been a focus of the Brain Trauma Foundation guidelines [16], it is an imperfect proxy for edema and treatment of the latter may become an important conceptual shift in the field as measures of cerebral edema (e.g., radiographic) improve. Nonetheless, depending on individual cerebral compliance, brain volume, and extent of edema development or lesion progression, both cerebral edema and contusion expansion can manifest as intracranial hypertension, irreversible brain injury, herniation, and death. Indeed, brain swelling, in large part due to cerebral edema and contusion volume, accounts for up to $50 \%$ of mortality in severe TBI [36-38].

Despite the extensive medical and financial burden, treatment options for cerebral edema and contusion expansion remain suboptimal, reactive, and largely unproven. There is no current treatment for diffuse axonal injury/traumatic microhemorrhages. Standard management protocols for cerebral edema and resultant intracranial hypertension after TBI frequently include hyperosmolar therapies (mannitol, hypertonic saline), sedation, hypothermia, neuromuscular paralysis, barbiturate coma, and decompressive craniectomy [14,16,39]. These therapies are neither targeted nor preventive, and they carry significant associated morbidities [14]. Some, such as decompressive craniectomy, are life-saving but do not stave off the underlying processes of secondary injury or functional impairment/disability [40-42]. Others, like hypothermia, may effectively control ICP but possibly increase the odds of worse outcome [43]. The modest mortality benefit proffered by tranexamic acid (TXA, 1.7\% absolute risk reduction) in CRASH3 (a recent large randomized controlled trial), while promising, did not extend to severe TBI or result in an improvement in functional outcome [44]. Evidence is not yet available from this study regarding whether TXA mitigated hemorrhage progression; smaller studies have yielded conflicting data [45], and results pending publication from another large trial (NCT01990768, $n=987$ ) disappointingly suggest no benefit on contusion expansion.

SUR1-TRPM4 is a unique cation channel emerging as a promising target for the treatment of cerebral edema and contusion expansion after TBI. In this narrative review, we briefly summarize molecular studies of SUR1-TRPM4, outlining the pathophysiology of this channel as it relates to cerebral edema and BBB integrity. We subsequently discuss SUR1-TRPM4 expression patterns in TBI and its potential utility as a theranostic biomarker. Research suggesting that genetic variation in $A B C C 8$ (encoding SUR1) and TRPM4 may play a role in secondary injury and outcome after TBI is 
also presented. Finally, existing preclinical and clinical studies specific to SUR1-TRPM4 inhibition via glibenclamide (GLI) in TBI are reviewed.

\section{Molecular Mechanisms of SUR1-TRPM4 in Models of CNS Injury}

Over the last two decades, a growing body of preclinical and clinical research has demonstrated a crucial role of SUR1-TRPM4 in central nervous system (CNS) pathology, including cerebral edema, BBB integrity, and neuroinflammation.

\subsection{SUR1-TRPM4, GLI, and Cerebral Edema}

Sulfonylurea receptor 1 (SUR1), encoded by $A B C C 8$, is a member of the adenosine triphosphate (ATP) binding cassette transporter superfamily that alone has no known function [46]. SUR1 itself is a regulatory subunit of multiple ion channels [47]. It undergoes obligate association with (and modulates) different pore-forming subunits to create heterologous ion channels in several cell types, of which SUR1-KIR6.2, an ATP sensitive potassium channel, has historically been the most extensively studied in the context of its activity in pancreatic $\beta$ cells and role in diabetes mellitus. SUR1-KIR6.2 mediates potassium efflux and hyperpolarizes cells; channel blockade by GLI stimulates insulin release, thus leading to its utility in the treatment of diabetes mellitus [46-49]. Of note, SUR1-KIR6.2 is also expressed in the CNS, including after TBI [50,51].

In 2001, seminal patch-clamp experiments by Chen and Simard identified a novel SUR1-regulated non-selective cation channel in adult rat astrocytes [52,53]. In these experiments, channel opening was mediated by nanomolar concentrations of intracellular $\mathrm{Ca}^{2+}$ and ATP depletion (leading to its initial designation of $\mathrm{NC}_{\mathrm{Ca} \text {-ATP }}$ [52,53]. This ion channel complex is now known to be a hetero-octameric structure comprising four SUR1 subunits, and four subunits of the pore-forming component, transient receptor potential melastatin 4 (TRPM4) [54]. SUR1-TRPM4 and SUR1-KIR6.2 have opposing physiological effects. SUR1-TRPM4 channel opening (e.g., by ATP depletion after treatment with sodium azide) is associated with indiscriminate influx of monovalent cations (predominantly sodium) and cell depolarization with subsequent cell swelling, blebbing, and oncotic cell death (Figure 1A) [46,52,53]. Recent work suggests that SUR1-TRPM4 co-assembles with the water channel, aquaporin-4 (AQP4), to form a hetero-multimeric complex that mediates water influx and resultant cellular swelling (Figure 1B) [55].

Unlike many other constitutively expressed SUR1 regulated channels in various systemic tissues, SUR1-TRPM4 is unique in that it is not normally present in the CNS, but undergoes de novo upregulation after CNS injury [36]. Upregulation of SUR1 with or without TRPM4 (hereafter SUR1 \pm TRPM4) has been demonstrated in multiple CNS cell types (neurons, astrocytes, endothelial cells, macrophages, microglia) and models of injury, including ischemic stroke [56-59], TBI [50,60-62], spinal cord injury (SCI) [63,64], intracerebral hemorrhage (ICH) [65], subarachnoid hemorrhage (SAH) [66,67], CNS metastases [68], cardiac arrest [69,70], hepatic failure [71], and encephalomyelitis [72-74] (Figure 1A). The increased expression in several cell-types of the neurovascular unit renders SUR1-TRPM4 a likely contributor across the spectrum of cerebral edema endotypes (reviewed elsewhere $[14,15,75]$ ), including cellular/cytotoxic edema, ionic edema, vasogenic edema, and eventually hemorrhagic transformation/progression with complete disintegration of the BBB and oncotic death of endothelial cells (Figure 1C) $[14,15,76]$.

Given its de novo upregulation, SUR1-TRPM4 inhibition has the potential to prevent or limit cerebral edema generation and hemorrhage progression at early stages of injury, with minimal side-effects. Channel blockade by gene silencing, deletion, or pharmacologic agents (primarily GLI) has demonstrated benefit in the aforementioned models of CNS injury $[46,56,57,60,61,64-70,72,73,77-88]$. GLI, also known as glyburide, inhibits SUR1-TRPM4 at nanomolar concentrations $\left(\mathrm{EC}_{50}=48 \mathrm{nM}\right)$ by increasing the probability of the channel's long closed state (frequency and duration), not by affecting channel conductance [53]. This potency is increased eight-fold at acidic $\mathrm{pH}$ levels $(\sim \mathrm{pH}=6.8)$ since GLI is a weak acid and protonation increases its lipid solubility $[46,56,89]$. Although GLI does not cross 
an intact BBB, the BBB is often disrupted in injured tissue (e.g., TBI, stroke). Moreover, the acidic $\mathrm{pH}$ of ischemic/injured CNS tissue facilitates drug transport across plasma membranes, and GLI can directly act on endothelial cells without traversing the BBB $[46,56,89,90]$. The effects of GLI on cerebral edema have been predominantly evaluated in ischemic stroke with promising results in edema reduction and BBB integrity in preclinical as well as clinical studies [56,57,78,89,91-96]. A Phase-3 trial of intravenous GLI (BIIB093) for malignant edema in ischemic stroke is ongoing (NCT02864953) [36]. Although less developed than the ischemic stroke literature, there is a rapidly growing body of research discussed in subsequent sections of this review, demarcating the importance of this channel and GLI in TBI.

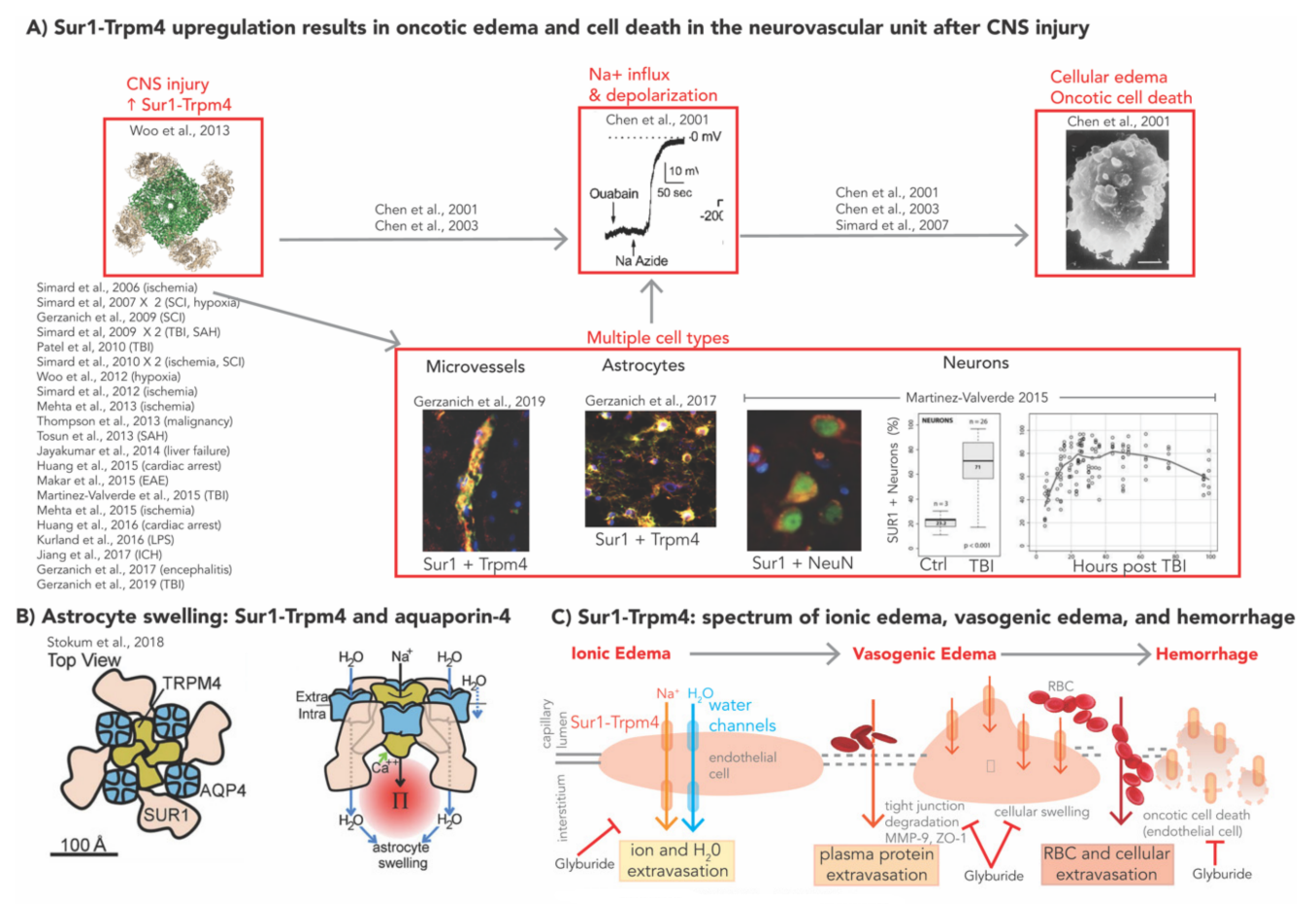

D) Functional impact of SUR1-TRPM4 vs SUR1-KIR6.2 heteromers

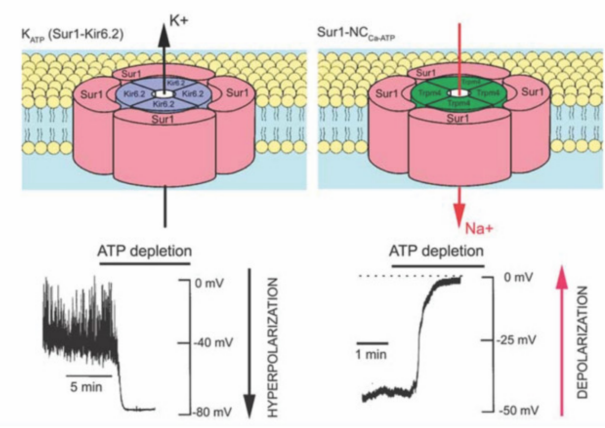

Figure 1. Overview of SUR1-TRPM4 and cerebral edema in central nervous system injury. (A) Sur1-Trpm4 upregulation results in oncotic edema and cell death in the neurovascular unit after CNS injury. This schematic contextualizes and lists the relevant research studies that have contributed towards understanding the basic SUR1-TRPM4 related molecular pathophysiology underlying cerebral edema and oncotic cell death after CNS injury. The processes themselves are highlighted in a red box: increased SUR1-TRPM4 expression in CNS injury has been reported in multiple cell types (microvessels, astrocytes, neurons). SUR1-TRPM4 activation results in sodium influx and cellular depolarization. This is associated with cellular edema, blebbing and oncotic cell death. Individual images adapted with permission from Chen et al., 2001, Martinez-Valverde et al., 2015, Gerzanich et al., 2017, Gerzanich et al., 2019 as referenced. (B) This is a proposed model of a SUR1-TRPM4-AQP4 hetero-multimeric complex showing AQP4 tetramers (blue channels) interposed within the SUR1-TRPM4 octamer (top 
view on the left, coronal view on the right). This model demonstrates SUR1-TRPM4 activation by increased intracellular $\mathrm{Ca}^{2+}$ (green arrow), which results in depolarization from $\mathrm{Na}^{+}$influx and raised intracellular oncotic pressure. This, in turn, drives intracellular water influx (blue arrows) via AQP4 channels causing astrocyte swelling. Adapted with permission from Stokum et al., 2018. (C) Schematic showing the spectrum of ionic edema, vasogenic edema, and blood brain barrier destruction resulting in hemorrhage. The role of SUR1-TRPM4 is highlighted. Ionic edema, driven by osmotic forces, involves transcapillary flux of ions across the capillary membrane into the interstitium as demonstrated by luminal and abluminal SUR1-TRPM4 (orange) and water (blue) channels. Cytotoxic edema/cellular swelling (shown in the endothelial cell) involves movement of ions into cells creating an osmotic gradient that requires water to enter (in neurons, astrocytes, or endothelial cells). Vasogenic edema results from water and proteinaceous fluid traversing across a disrupted blood brain barrier that may occur in the setting of tight-junction degradation as well as oncotic edema of endothelial cells. In its extreme forms, when oncotic edema and cell death occurs in endothelial cells (shown) and astrocytes podocytes (not shown), complete breakdown of the blood-brain barrier results in erythrocyte extravasation, and hemorrhage into the interstitium. All these processes have been shown to involve SUR1-TRPM4, and thus may be inhibited by glibenclamide (also known as glyburide). (D)Schematic diagram of the two SUR1 regulated heteromeric channels expressed in the CNS after TBI: SUR1-KIR6.2 vs. SUR1-TRPM4. There are four subunits of SUR1 (pink) and four subunits of the pore-forming subunits KIR6.2 (lavender, left) or TRPM4 (green, right). ATP depletion activates both channels. SUR1-TRPM4 activation results in cell depolarization; the opposite effect (hyperpolarization) is achieved with SUR1-KIR6.2 activation. Adapted with permission from Simard et al., Sulfonylurea Receptor 1 in Central Nervous System Injury: A Focused Review. J Cereb Blood Flow Metab. 32 (9): 1699-1717. Copyright 2012 (SAGE Journals). $\mathrm{CNS}=$ central nervous system; $\mathrm{EAE}=$ experimental autoimmune encephalitis; $\mathrm{ICH}=$ intracranial hemorrhage; LPS = lipopolysaccharide; $\mathrm{SAH}=$ subarachnoid hemorrhage, $\mathrm{SCI}=$ spinal cord injury, $\mathrm{TBI}=$ traumatic brain injury.

\subsection{SUR1-TRPM4: Neuroinflammation and BBB Integrity}

Some upstream molecular mechanisms related to SUR1-TRPM4 upregulation have been characterized in hypoxia/ischemia, SAH, and mechanical stress (Figure 2A) [67,97-99]. Beyond mechanisms of edema and oncotic cell death, SUR1-TRPM4 signaling and inhibition by GLI have also been identified as relevant in apoptotic cell death pathways involving Bcl-associated $\mathrm{X}$ protein (BAX) and caspase-3 (Figure 2A) [60,67,83], neuroinflammation (Figure 2A,B) $[66,67,72,73,100,101]$, and BBB integrity (Figure 2A,C) via matrix metalloproteinase (MMP)-9 secretion, zona-occludens-1 (ZO-1) expression and redistribution $[66,67,83,102]$ in different models of CNS injury, including SAH, TBI, ischemia-reperfusion (I/R), inflammation, and encephalomyelitis. However, the details are complex and remain incompletely understood, particularly in TBI. Nonetheless, they are important to explore given the potential implications for multifactorial benefits of SUR1-TRPM4 inhibition (e.g., with GLI) which may vary based on temporal, spatial and individual activation of these molecular networks.

\subsubsection{Neuroinflammation}

The complex role of post-traumatic neuroinflammation involves both deleterious secondary injury as well as repair/recovery, thus making it a nuanced but important target for therapeutic modulation [103]. While not studied specifically in TBI, in vitro and in vivo models of lipopolysaccharide induced neuroinflammation demonstrate microglial activation of toll-like receptor 4 (TLR4), and de novo upregulation of SUR1-TRPM4, initiating a signaling cascade that increases nitric oxide (NO) production and contributes to harmful peroxynitrite-mediated protein radical formation $[100,104,105]$. TLR4 induced cellular depolarization via SUR1-TRPM4 decreases the inward driving force for intracellular $\mathrm{Ca}^{2+}$ influx. This results in low-amplitude repetitive oscillations in $\mathrm{Ca}^{2+}$, which activates calcineurin (a phosphatase). Calcineurin dephosphorylates nuclear factor of activated T-cells (NFATc1), allowing nuclear translocation and NFATc1-dependent upregulation of nitric oxide synthase-2 (Nos2) mRNA, NOS2 protein, and NO (Figure 2B, green) [100]. In this 
model, SUR1-TRPM4 inhibition (via GLI) increased intracellular $\mathrm{Ca}^{2+}$, as predicted, but reduced NFATc1, likely via persistent activation of calmodulin dependent protein kinase-II (CAMKII) (Figure 2B, red). Activated CAMKII phosphorylates and inactivates calcineurin, thereby preventing calcineurin dependent NFATc1 dephosphorylation and nuclear translocation. Here, GLI reduced microglial NOS2 expression/NO production, suggesting a mechanism by which it may be protective in other neuroinflammatory conditions such as TBI.

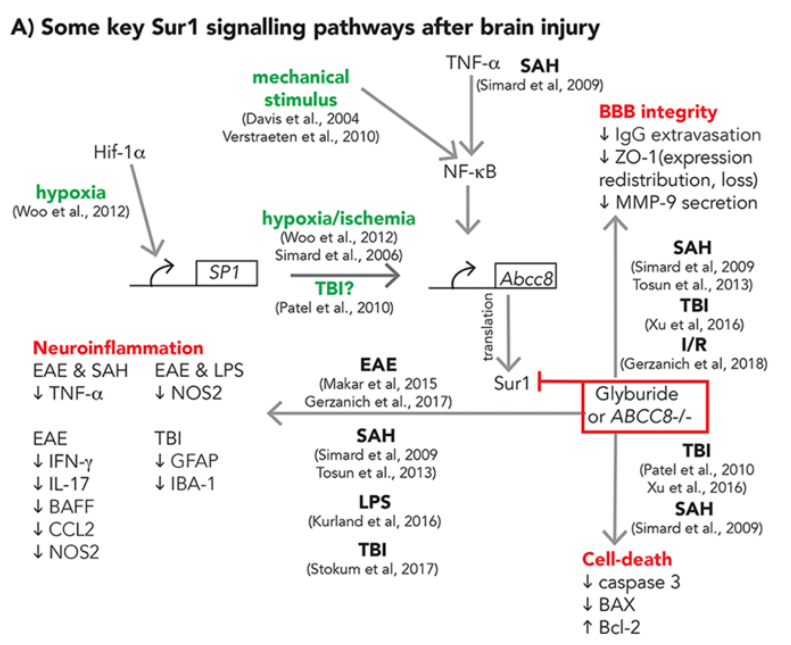

B) Neuroinflammation Sur1-Trpm4 and nitric oxide synthase-2

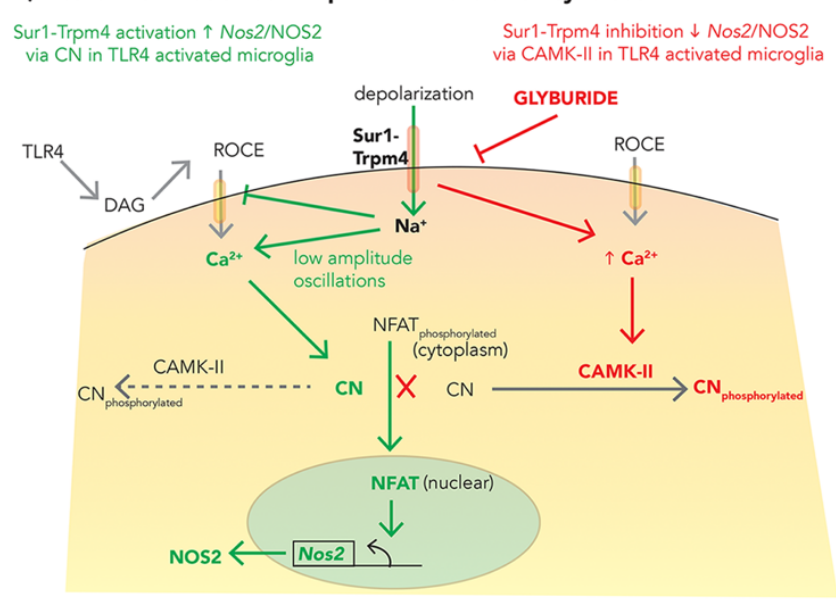

C) Blood brain barrier integrity: Sur1-Trpm4 and matrix metalloproteinase-9

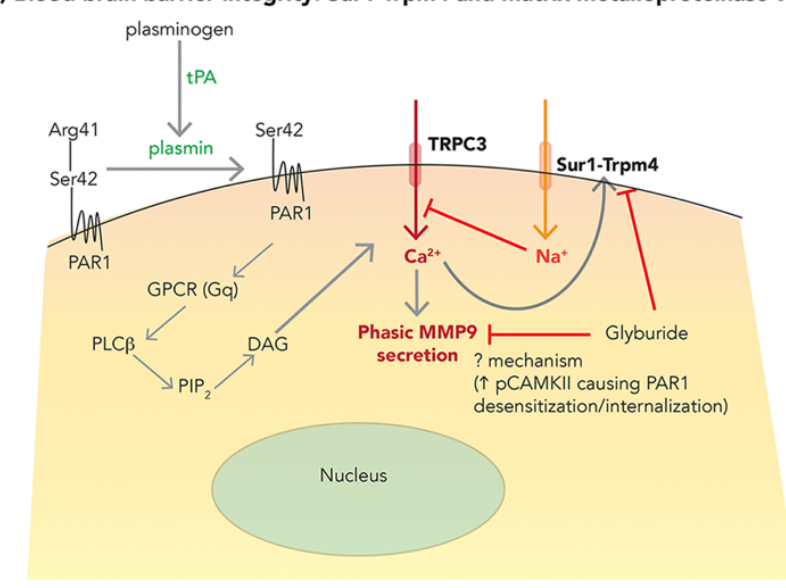

Figure 2. Putative SUR1 molecular signaling pathways beyond cerebral edema in brain injury. (A) Some key Sur1 signaling pathways after brain injury. This schematic illustrates upstream regulators of Sur1 
(Abcc8) transcription such as Hif1- $\alpha$, SP1 and TNF- $\alpha$. The precipitating injury (e.g., hypoxia, TBI, mechanical stimulus) is listed in green. Downstream consequences of inhibiting upregulated Sur1 (via glyburide/glibenclamide or genetic knockout) on three major categories (blood brain barrier integrity, neuroinflammation, and cell death) are shown in red. Specific references that have demonstrated these effects are listed contextually and categorized by disease model. (B) Neuroinflammation, Sur1-Trpm4, and nitric oxide synthase-2 (NOS2). This illustration shows effects of Sur1-Trpm4 activation on nitric oxide (NO) production in microglial cells (pathway in green). Toll like receptor-4 (TLR4) activation induces de novo upregulation and activation of Sur1-Trpm4. Resultant depolarization, decreases the inward driving force for $\mathrm{Ca}^{2+}$, yielding low-amplitude repetitive oscillations of $\mathrm{Ca}^{2+}$. This activates calcineurin $(\mathrm{CN})$, which dephosphorylates cytoplasmic NFAT and allows nuclear translocation. Nuclear NFAT is a transcription factor that upregulates transcription of Nos2, and thereby increases expression of NOS2 and production of NO. Inhibition of Sur1-Trpm 4 by glyburide (glibenclamide) shown in the red pathway, increases intracellular calcium which activates calmodulin dependent protein kinase-II (CAMKII). CAMKII phosphorylates CN thereby inactivating it and preventing dephosphorylation and nuclear translocation of NFAT. Thus, Nos2 transcription is inhibited and NO production reduced. (C) Blood-brain barrier integrity: Sur1-Trpm4 and matrix metalloproteinase-9. Tissue plasminogen activator (tPA) converts plasminogen to plasmin, resulting in the cleavage (at Arg41) of protease activated receptor 1 (PAR1). Activated PAR1, via G protein receptor signaling (GPCR), phospholipase C (PLC), phosphatidylinositol biphosphate (PIP2) and diacylglycerol (DAG) activates transient receptor potential channel-3 (TRPC3, red) facilitating calcium entry and phasic MMP-9 secretion. Sur1-Trpm4 activation (orange) causing $\mathrm{Na}^{+}$influx and depolarization, results in negative feedback of TRPC3, thereby inhibiting $\mathrm{Ca}^{2+}$ influx. Inhibition via glyburide (glibenclamide) despite increasing the drive for $\mathrm{Ca}^{2+}$ influx, reduces phasic MMP-9 secretion via a yet to be determined mechanism. One potential hypothesis includes phosphorylated CAMKII mediated PAR1 desensitization and internalization. BAX $=\mathrm{Bcl}$-associated $\mathrm{X}$ protein; $\mathrm{BCL} 2=\mathrm{b}$ cell lymphoma $2 ; \mathrm{CAMKII}=$ calmodulin dependent protein kinase-II; CCL-2 = chemokine (C-C motif) ligand 2; CN = calcineurin; DAG = diacylglycerol; EAE $=$ experimental autoimmune encephalitis; GFAP $=$ glial fibrillary acidic protein; $\mathrm{GPCR}=\mathrm{G}$ protein coupled receptor; HIF-1 $\alpha=$ hypoxia inducible factor- alpha; IBA-1 = ionized calcium binding adaptor molecule 1; IFN- $\gamma=$ interferon gamma; LPS = lipopolysaccharide; MMP-9 = matrix metalloproteinase-9; NFAT $=$ nuclear factor of activated T-cells; $\mathrm{NO}=$ nitric oxide; NOS2 = nitric oxide synthase-2; PAR1 = protease activated receptor 1 ; PIP2 = phosphatidylinositol 4,5 biphosphate; PLC $=$ phospholipase C; $\mathrm{ROCE}=$ receptor operated calcium entry; $\mathrm{SAH}=$ subarachnoid hemorrhage; $\mathrm{SCI}=$ spinal cord injury; $\mathrm{Sp} 1=$ specificity protein 1 ; SUR1 = Sulfonylurea receptor 1 ; TBI = traumatic brain injury; TLR4 = toll like receptor 4 ; TNF- $\alpha=$ tissue necrosis factor alpha; $\mathrm{tPA}=$ tissue plasminogen activator; TRPC3 = short transient receptor potential channel-3; TRPM4 = transient receptor potential melastatin 4; ZO-1 = zona occludens 1.

\subsubsection{BBB Integrity}

Ongoing BBB breakdown perpetuates hemorrhage progression and contusion expansion after TBI. Although SUR1-TRPM4 contributes to BBB permeability via oncotic death of endothelial cells [14,15,76], it has also been implicated in this process in connection with other mechanisms involving ZO-1 [67,83], MMP-9 and/or tissue plasminogen activator (tPA) [91,95,102] (Figure 2A). MMP-9 is a zinc-dependent endopeptidase (collagenase) zymogen, widely implicated in extracellular matrix degradation and BBB disruption in many CNS diseases. However, its overlap with SUR1-TRPM4 requires further investigation, particularly in TBI [14,106]. While neutrophils are a major source of MMP-9 [107], it is also secreted from neurons, microglia, pericytes, and endothelial cells; indeed, it is prominently expressed in the microvascular endothelium during the first $24 \mathrm{~h}$ after focal ischemia [102,108]. In a model of I/R, tPA induced SUR1-TRPM4 channel opening and MMP-9 secretion from activated brain endothelial cells (Figure 2C) [102]. Conversion of plasminogen to plasmin (a serine protease) by tPA then induced canonical activation of protease activated receptor 1 (PAR1) by cleavage at Arg41. This triggered phasic MMP-9 secretion, and also opened SUR1-TRPM4 channels. The latter, via $\mathrm{Na}^{+}$influx and a negative 
feedback loop, decreases the electrochemical driving force for intracellular $\mathrm{Ca}^{2+}$ influx. SUR1-TRPM4 inhibition by GLI (and shRNA against $A b c c 8$ ) unexpectedly reduced phasic MMP-9 secretion from activated endothelium. Although the precise mechanism of the benefit remains unestablished, it is thought to be related to increased phosphorylated-CamKII and subsequent desensitization and internalization of PAR1 [102]. Nonetheless, it remains to be determined whether/to what extent this mechanism and GLI modulates BBB permeability after TBI. While other protease-mediated interactions (such as calpains) are also indisputably important contributors to BBB permeability after TBI, unlike MMP-9, they have not been evaluated in the context of SUR1-TRPM4 interactions. The link between caspases and SUR1-TRPM4 \pm GLI have been evaluated in the context of apoptosis, not BBB permeability (Section 2.2).

\section{SUR1-TRPM4 Expression in TBI}

Patterns of increased SUR1 \pm TRPM4 expression in post-traumatic human contusions are similar to those described in rat TBI models (Table 1) [50,51,60-62]. Scientific research understanding the complexity of SUR1's association with its pore-forming subunit partners in TBI is limited, but rapidly evolving. As discussed in this section, previous studies have identified overexpression of KIR6.2 and SUR1 in post-traumatic human contusions (particularly astrocytes), however TRPM4 was not evaluated by this group [51,62]. In a separate study, TRPM4 overexpression was reported in a rodent model of TBI [109]. Determining precise temporal, spatial, and cellular expression patterns of both SUR1-TRPM4 and SUR1-KIR6.2 (and their functional implications if expressed simultaneously) after TBI is particularly important given the opposite effects of the two channels (Figure 1D). This will also impact their potential utility as biomarkers. In 2019, Gerzanich et al. evaluated SUR1, TRPM4, and KIR6.2 protein expression patterns in human contusion as well as rodent models of TBI; their findings are discussed in detail below (summarized in Table 1) [50]. Based on current information from these studies, SUR1-TRPM4 and SUR1-KIR6.2 multimers are not always expressed together after TBI, however simultaneous expression of SUR1, TRPM4, and KIR6.2 have been reported within certain cell-types [50].

In general, SUR1 colocalization (by immunofluorescence) and coassembly (by FRET imaging) with TRPM4 but not KIR6.2 has been noted in microvessels. Microglial cells and astrocyte tend to express all three channel subunits-SUR1, TRPM4, and KIR6.2-the functional implications of which are currently unestablished. Astrocyte expression has been most prominently noted in penumbral tissue. Increased endothelial expression of channel subunits typically preceded expression in microglia or astrocytes; this may impact the timing of edema endotypes (vasogenic \pm contusion expansion vs. cellular/cytotoxic), neuroinflammatory responses and repair mechanisms.

In the following subsections, expression of post-traumatic SUR1, TRPM4, and KIR6.2 is discussed-including 'penumbral' expression. A traditional understanding of traumatic 'penumbra' typically refers to brain tissue surrounding the primary lesion (e.g., contusion) that is damaged, ischemic, or susceptible to various forms of secondary injury but retains the potential for recovery i.e., the impact of insult on the 'penumbra' is not irreversible. However, this definition is likely to evolve and develop molecular sophistication. In early work on the SUR1-TRPM4 pathway, Patel et al., defined penumbra (at time $=0$ ) as the region of tissue outside primary contusion where NFKB and SP1 were upregulated and secondary hemorrhage occurred. In this work, a parapenumbra was also identified where SP1 was upregulated but NFKB was absent—here, cell death may occur however hemorrhage progression was absent [60]. Recent work by the same group classifying human tissue (not at time $=0$, but rather after secondary hemorrhage was completed), operationally defined the penumbra as GFAP+ and TUNEL- tissue [50]. Strictly speaking, since secondary hemorrhage had already occurred, this tissue would be more consistent with parapenumbra based on the definition used in the earlier study. 
Table 1. SUR1, TRPM4, and KIR6.2 expression in rodent and human contusional TBI.

\begin{tabular}{|c|c|c|c|c|c|c|}
\hline & \multicolumn{3}{|c|}{ Rat Contusion } & \multicolumn{3}{|c|}{ Human Contusion } \\
\hline & Increased $(\mathrm{Y} / \mathrm{N})$ & Peak (h Post Injury) & Ref & Increased $(\mathrm{Y} / \mathrm{N})$ & Peak (h Post Injury) & Ref \\
\hline \multicolumn{7}{|l|}{ SUR1 } \\
\hline Neurons & Y & $12-24 \mathrm{~h}$ & $\begin{array}{l}\text { Simard et al., } 2009 \text { [61] } \\
\text { Patel et al., } 2010 \text { [60] }\end{array}$ & Y & $24 \mathrm{~h}$ & Martinez-Valverde et al., 2015 [62] \\
\hline $\begin{array}{l}\text { GFAP+ Glia } \\
\text { (Astrocytes) }\end{array}$ & $\mathrm{Y}$ & $72 \mathrm{~h}$ (penumbra) & Gerzanich et al., 2019 [50] & $\mathrm{Y}$ & $\begin{array}{l}\uparrow \text { with time }(100 \mathrm{~h}) \\
\text { GFAP+ penumbra } \\
\text { (prominent) }\end{array}$ & $\begin{array}{l}\text { Martinez-Valverde et al., } 2015 \text { [62] } \\
\text { Gerzanich et al., } 2019 \text { [50] }\end{array}$ \\
\hline Microvessels & $\mathrm{Y}$ & 6-12 h (core) & Gerzanich et al., 2019 [50] & Y & stably $\uparrow$ GFAP- core & $\begin{array}{l}\text { Martinez-Valverde et al., } 2015 \text { [62] } \\
\text { Gerzanich et al., 2019 [50] }\end{array}$ \\
\hline Microglia & $\mathrm{Y}$ & $72 \mathrm{~h}$ (core) & Gerzanich et al., 2019 [50] & Y & $\begin{array}{l}\uparrow \text { with time }(100 \mathrm{~h}) \\
\text { GFAP- core }\end{array}$ & $\begin{array}{l}\text { Martinez-Valverde et al., } 2015 \text { [62] } \\
\text { Gerzanich et al., 2019 [50] }\end{array}$ \\
\hline \multicolumn{7}{|l|}{ TRPM4 } \\
\hline Neurons & Unk & - & - & Unk & - & - \\
\hline $\begin{array}{l}\text { GFAP+ Glia } \\
\text { (Astrocytes) }\end{array}$ & Y & $72 \mathrm{~h}$ (penumbra) & Gerzanich et al., 2019 [50] & Y & GFAP + penumbra & Gerzanich et al., 2019 [50] \\
\hline Microvessels & $\mathrm{Y}$ & $24 \mathrm{~h}$ & Gerzanich et al., 2019 [50] & Y & $\begin{array}{l}\text { GFAP-core } \\
\text { GFAP-core }\end{array}$ & Gerzanich et al., 2019 [50] \\
\hline Microglia & Y & $72 \mathrm{~h}$ (core) & Gerzanich et al., 2019 [50] & Y & $\begin{array}{l}\text { GFAP+ penumbra } \\
\text { (some) }\end{array}$ & Gerzanich et al., 2019 [50] \\
\hline \multicolumn{7}{|l|}{ KIR6.2 } \\
\hline Neurons & Unk & - & & $\mathrm{N}$ & - & $\begin{array}{c}\text { Castro et al., } 2018 \text { [51] } \\
\text { Gerzanich et al., } 2019 \text { [50] }\end{array}$ \\
\hline $\begin{array}{l}\text { GFAP+ Glia } \\
\text { (Astrocytes) }\end{array}$ & Y & $72 \mathrm{~h}$ (penumbra) & Gerzanich et al., 2019 [50] & Y & $\begin{array}{c}\text { Unk } \\
\text { GFAP+ penumbra }\end{array}$ & $\begin{array}{l}\text { Castro et al., } 2018 \text { [51] } \\
\text { Gerzanich et al., } 2019 \text { [50] }\end{array}$ \\
\hline Microvessels & $\mathrm{N}$ & - & Gerzanich et al., 2019 [50] & $\mathrm{N}$ & - & $\begin{array}{l}\text { Castro et al., } 2018 \text { [51] } \\
\text { Gerzanich et al., } 2019 \text { [50] }\end{array}$ \\
\hline Microglia & Y & $72 \mathrm{~h}$ (core) & Gerzanich et al., 2019 [50] & $\underset{Y}{\text { Mixed }}$ & $\begin{array}{l}\text { - (not different vs. } \\
\text { controls) } \\
\text { GFAP- core }\end{array}$ & $\begin{array}{c}\text { Castro et al., } 2018 \text { [51] } \\
\text { Gerzanich et al., } 2019 \text { [50] }\end{array}$ \\
\hline
\end{tabular}

$\mathrm{h}=$ hour, $\mathrm{N}=$ no; unk = unknown; $\mathrm{Y}=$ yes,$\uparrow=$ increased 


\subsection{Increased SUR1 \pm TRPM4 Expression in Rodent Models of TBI}

To date, evaluation of SUR1 \pm TRPM4 expression in preclinical TBI has occurred exclusively in rats and predominantly in models of focal cortical impact, with only a single study in diffuse central fluid percussion injury (FPI) $[50,60,61,109]$. Despite different TBI severity models in these studies, SUR1 $[50,60,61]$ and TRPM4 $[50,109]$ are consistently upregulated in different cell types of the neurovascular unit.

In focal contusion ( $10 \mathrm{~g}$ weight, $5 \mathrm{~cm}$ drop, $1 \mathrm{~m} / \mathrm{s}$ impact velocity), SUR1 expression was observed in tissue immediately beneath the impact as early as $3 \mathrm{~h}$, predominantly in microvessels [61]. By $24 \mathrm{~h}$, this became prominent in both neurons and capillaries in regions beyond the ipsilateral cortex, including the hippocampus, thalamus, and contralateral dorsomedial thalamus [61]. Further work in contusion by the same group (controlled cortical impact, CCI, $5 \mathrm{~mm}$ impactor, $4.5 \mathrm{~mm}$ depth, $1 \mathrm{~m} / \mathrm{s} \mathrm{impact}$ velocity) parsed out temporal and cellular differences in SUR1-TRPM4 expression in contusion core (GFAP-, TUNEL+) vs. penumbra (GFAP+, TUNEL-) as illustrated in Figure 3A [50]. In the core, SUR1 expression peaked at $6 \mathrm{~h}$, remained elevated at $12 \mathrm{~h}$, declined at $24 \mathrm{~h}$ and increased again at $72 \mathrm{~h}$. During the first $24 \mathrm{~h}$, SUR1 expression colocalized with TRPM4, and was predominantly noted in microvessels, which may have important implications for the treatment of vasogenic edema (see Section 3.5). There was no evidence of microvascular KIR6.2 expression. By $72 \mathrm{~h}$, SUR1 expression was primarily noted in small round cells thought to be microglia/macrophages. Here, double labelling with TRPM4 or KIR6.2 demonstrated that these cells expressed all three channel subunits. In contrast, penumbral expression of SUR1 at all timepoints was noted in GFAP+ stellate cells thought to be astrocytes. These cells also expressed all three channel subunits: SUR1, TRPM4, and KIR6.2. Additional research is warranted to investigate the functional interactions and implications of this co-expression in both astrocytes and microglia/macrophages post-TBI, particularly since similar findings have been noted in human post-traumatic tissue (Section 3.2).

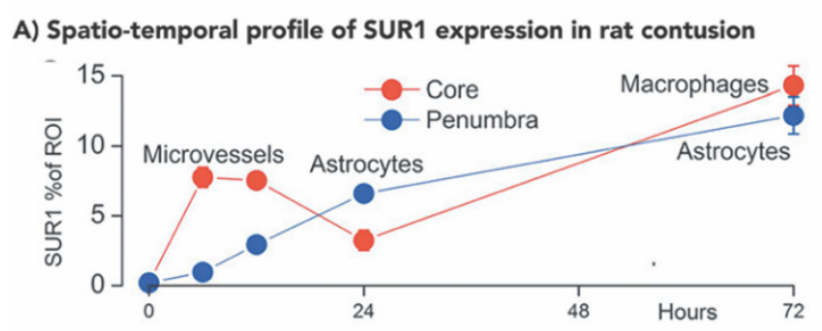

C) Reduced blood extravasation (3h -24h) with GLI

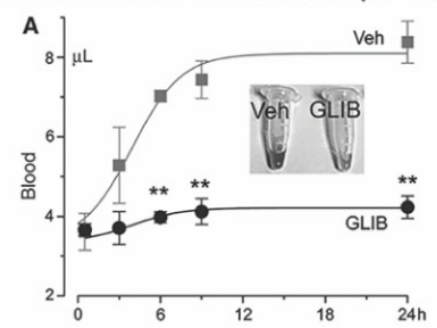

B) Endothelial expression of SUR1 in human contusion
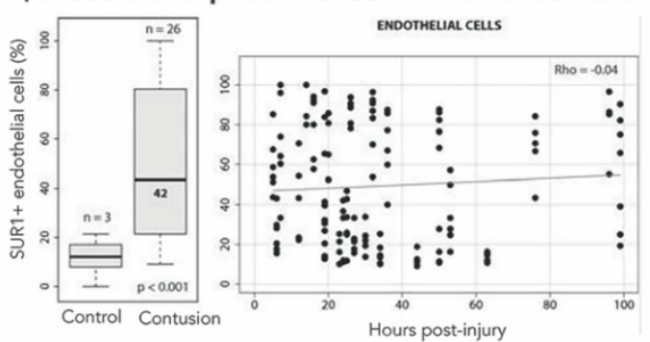

D) FRET colocalization of microvascular SUR1 and TRPM4 in human contusion

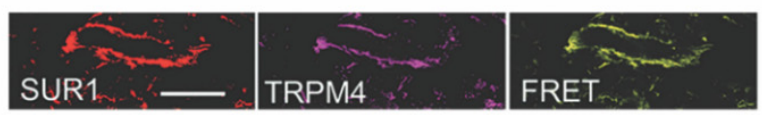

Figure 3. SUR1 expression and inhibition in contusion TBI. (A) Spatio-temporal profile of SUR1 expression in rat contusion. Graph of quantified SUR1 expression in core contusion (red) demonstrating prominent early expression in microvessels that decreases by $24 \mathrm{~h}$, and increased expression in macrophages by $72 \mathrm{~h}$. SUR1 expression in penumbra (blue) is predominantly astrocytic at all time points, with highest levels observed at $72 \mathrm{~h}$. Adapted with permission from Gerzanich et al., 2019. (B) Endothelial expression of SUR1 in human contusion. The left panel shows a box-plot demonstrating a significantly higher proportion of SUR1+ endothelial cells in contusion vs. control samples $(p<0.001)$. The panel on the right demonstrates no correlation between \% of SUR1+ endothelial cells and time since injury. Adapted with permission from Martinez-Valverde et al., 2015. (C) Reduced blood extravasation 
(3-24 h) with glibenclamide (GLI). Graph demonstrating mean quantified volume of extravasated blood at $0,3,6,12$, and $24 \mathrm{~h}(\mathrm{n}=3$ /group at all time points except 5/group at $24 \mathrm{~h}$ ) in vehicle (grey squares) vs. GLI treated (black circles) rats after focal cortical impact. There is minimal increase in extravasated blood in the GLI treated group at $24 \mathrm{~h}$ vs. baseline. However, extravasated blood volume almost doubles by $24 \mathrm{~h}$ in vehicle rats. Differences between extravasated blood volumes in GLI treated vs. vehicle rats appear by $3 \mathrm{~h}$, become significant by $6 \mathrm{~h}$, and persist at $24 \mathrm{~h}$. Error bars $=$ standard error. ** $=p<0.01$. Adapted with permission from Simard et al., 2009. (D) ImmunoFRET images from human contusion tissue for SUR1 (red) and TRPM4 (purple) demonstrating co-assembly of these heteromers (yellow) in a microvessel. Scale bar $=100 \mu \mathrm{m}$. Adapted with permission from Gerzanich et al., 2019.

SUR1 protein and $A b c c 8 \mathrm{mRNA}$ expression in a milder model of focal impact were also elevated vs. sham [60]. Here, it was preceded by transcription factor specificity protein-1 (Sp1) expression, and was predominantly noted in hippocampal neurons at $6 \mathrm{~h}$, peaking at $12 \mathrm{~h}$, and declining by $24 \mathrm{~h}$ post injury. While SUR1 expression has not been quantified in FPI, TRPM4 results were surprising in that increased expression persisted for up to 8 weeks after injury [109]. In this model, expression was noted in astrocytes, with differences noted between hippocampal grey vs. white matter (fissure). Higher TRPM4 levels were observed in the latter. TRPM4 expression was correlated with astrocyte swelling: TRPM4+ astrocytes had nearly double the soma size $\left(p=1.2 \times 10^{-12}\right)$ but did not undergo cell death. Future work exploring physiologic consequences of TRPM4 and/or KIR6.2 colocalization with SUR1 in this model could be valuable to guide therapeutic studies of channel inhibition in diffuse injury.

\subsection{Increased Human SUR1 $\pm T R P M 4$ Expression in TBI}

In a cohort of 26 patients with contusion, neuronal SUR1 expression was almost threefold greater in contusions vs. controls (meningioma, schwanomma, rhabdoid tumor, $p<0.001$ ) [62]. While detected as early as $6 \mathrm{~h}$ post injury, neuronal SUR1 expression peaked at $24 \mathrm{~h}$ after which it stabilized. Early SUR1 expression was also detected in CD31 + endothelial cells (again, approximately threefold greater expression vs. controls). However, no temporal trend was noted in these cells; microvascular SUR1 expression remained elevated up to $100 \mathrm{~h}$ post-injury (Figure 3B). Semiquantitative immunohistochemistry did not detect any SUR1 expression in control GFAP+ glial cells (astrocytes), activated microglia/macrophages or neutrophils, whereas moderate SUR1 expression was found in all these cells-types after contusion. Most circulating neutrophils were SUR1 negative; however, those from brain parenchyma were SUR1 positive. The same group also identified KIR6.2 overexpression in contusional GFAP+ glial cells (astrocytes), consistent with findings in rodents. TRPM4 expression was not assessed in this study [51].

Deconstructing regional expression of SUR1, TRPM4, and KIR6.2 in contusion core vs. penumbra, analogous to the rodent experiments described above, yielded similar results [50]. Although temporal trends were not evaluated in human tissue, core lesions demonstrated SUR1 and TRPM4 expression, colocalization and heteromer coassembly (by FRET imaging) in microvessels (Figure 3D). KIR6.2 was not detected in these microvessels. SUR1 and TRPM4 colocalization was also demonstrated in CD68+ small round cells, i.e., microglia/macrophage; however, all three channel subunits (including KIR6.2) were expressed in these cells. Penumbral samples prominently expressed SUR1 in astrocytes, with minimal levels in microvessels or microglia/macrophages. TRPM4 and KIR6.2 levels were also increased in astrocytes, and FRET experiments demonstrated heteromers of both SUR1-TRPM4 and SUR1-KIR6.2. Neuronal expression was not evaluated in this study other than noting minimal expression of KIR6.2.

\subsection{SUR1-TRPM4 Theranostic Biomarker Potential after TBI}

De novo upregulation of SUR1-TRPM4 after TBI (and other CNS disorders) affords it unique potential as a theranostic biomarker. However, serum \pm CSF biomarker research regarding this pathway in TBI is currently in its infancy. Pilot work demonstrated markedly elevated SUR1 levels in cerebrospinal fluid (CSF) of 28 patients after TBI vs. undetectable levels in 15 controls with normal 
pressure hydrocephalus (Figure 4A) [110]. Remarkably, in some patients, ICP trajectories mirrored SUR1 expression patterns after a temporal delay (Figure 4B). SUR1 levels were associated with radiographic edema detected on CT scans, and with the initial degree of intracranial hypertension. SUR1 trajectories (rather than absolute values) were associated with both intracranial hypertension and outcome after TBI. No patients with declining SUR1 levels between 48-72 $\mathrm{h}$ had any episodes of intracranial hypertension or unfavorable outcome. Unfortunately, assessment of therapeutic intensity level was not available in this study, and the mechanism of SUR1 entry into the CSF remains unknown. While it is possible that the results relating SUR1 to measures of edema reflect an epiphenomenon, there did not appear to be a correlation between SUR1 level and initial injury severity as measured by the Glasgow coma scale (GCS) score (Figure 4C). Despite the multiple limitations of this exploratory study, including its single center and associative nature, the results are consistent with preclinical work and known pathophysiology in human studies, and warrant further exploration in larger cohorts. It is currently premature to consider SUR1 a biomarker in TBI, and further extensive functional and mechanistic studies are necessary to determine its utility. This work should include detailed phenotypic evaluation and take into consideration the multimeric expression of both SUR1-TRPM4 as well as SUR1-KIR6.2. Since SUR1 is the regulatory subunit of both these heteromeric channels (with opposite functional effects), the utility of SUR1 alone may be limited and dampen enthusiasm for clinical use in isolation. Additionally, it may be valuable to correlate SUR1-related biomarkers with several existing and promising biofluid markers of neuronal (ubiquitin C-terminal hydrolase-L1 [UCHL1], neuron specific enolase), astroglial (S100B protein, GFAP), axonal (neurofilaments, myelin-basic protein), and neurodegenerative (P- and T-tau) injury [111]. Since SUR1 heteromers with TRPM4 and KIR6.2 have been identified post-TBI in multiple cell types, correlation of biofluid levels with known markers of neuronal or astroglial injury may be informative. UCHL1 in particular may be valuable to correlate with SUR1-related biomarkers given its time course of upregulation over $24 \mathrm{~h}$ and its utility as an acute biomarker in severe TBI [111,112]. The discovery and validation of SUR1-pathway related biomarkers in the serum and CSF may become easier as the sensitivity and specificity of proteomic and transcriptomic technology improves. SUR1 quantification in serum/plasma samples after TBI has not yet been published, but represents another potentially important avenue for future research.

Other biomarkers related to SUR1-TRPM4 pathophysiology may also be important in TBI, but are currently understudied. In a recent Phase-2 trial of large hemispheric infarction, plasma MMP-9 levels were reduced in patients treated with intravenous GLI [91]. While largely unexplored in TBI, given the importance of MMP-9 in BBB integrity, vasogenic edema, and contusion expansion related secondary injury in this disease, MMP-9 may be a promising biomarker to investigate. A small study in 8 TBI patients demonstrated declining microdialysate MMP-9 levels over time, with a trend towards higher levels in patients with severe brain tissue hypoxia [113]. Another study in 12 TBI patients reported higher levels of pericontusional (vs. contralateral) microdialysate MMP-9 levels, but did not evaluate a relationship with cerebral edema or contusion expansion [114].

\subsection{Impact of Genetic Variation in ABCC8 (Encoding SUR1) and TRPM4 in TBI}

As mentioned earlier, approximately $65 \%$ of TBI outcome variability remains unexplained by existing large multivariable models that incorporate primarily non-modifiable injury characteristics identified on presentation [2,3]. It follows that the host-response is a key factor in regulating secondary injury processes such as cerebral edema and contusion expansion that significantly influence outcome after TBI. Genetic variation is increasingly recognized as an important contributor to variability in post-traumatic host response [28,115-124].

Targeted investigations into the impact of $A B C C 8$ and TRPM4 genetic variation on cerebral edema, intracranial hypertension, and outcome after TBI have been performed in 385-485 patients with severe TBI from a single-center [28,122-124]. Genotyped ABCC8 single nucleotide polymorphisms (SNPs) were distributed across the length of the gene with good coverage (Figure 5A) [122,123]. The majority of these were tag-SNPs (i.e., representative SNPs in high linkage disequilibrium [LD] with a 
group of SNPs/ haplotype). Eight regionally clustered ABCC8 SNPs (rs4148622, rs1799857, rs11024286, rs2237982, rs2283261, rs2283258, rs3819521, rs7105832) were significantly associated with measures of CT edema, ICP and/or outcome (GOS) after TBI [122,123]. Minor allele frequencies were $25-40 \%$. Effect sizes were large and withstood the B-Y correction for multiple comparisons. These significant SNPs (and their associated 33 proxy-SNPs in LD) were all located upstream, between intron-2 and intron-15 of the 39 exon gene (Figure 5A) [123]. The spatially clustered polymorphisms were in LD with regions of DNA encoding the SUR1 site and transmembrane domain 0 (juxtaposing the TRPM4 binding site) (Figure 5B). This geography is in stark contrast to most SNPs reported in disorders of glucose metabolism, approximately two-thirds of which regionally cluster downstream towards introns/exons 16-39, in closer proximity with the adjacent gene KCNJ11 (encoding KIR6.2). The true implications of the identified ABCC8 SNPs in TBI remains unknown. Other than rs1799857 (synonymous variant in exon-12), the remaining significant SNPs are intronic, consistent with known SNP distributions in the human genome. Given their strategic spatial location, they may have important functional, splicing or gene expression/regulatory consequences. Further research is necessary to evaluate their impact in biological models and identify causal variants of disease.

A: $\uparrow$ CSF Sur1 levels in TBI vs absent in controls
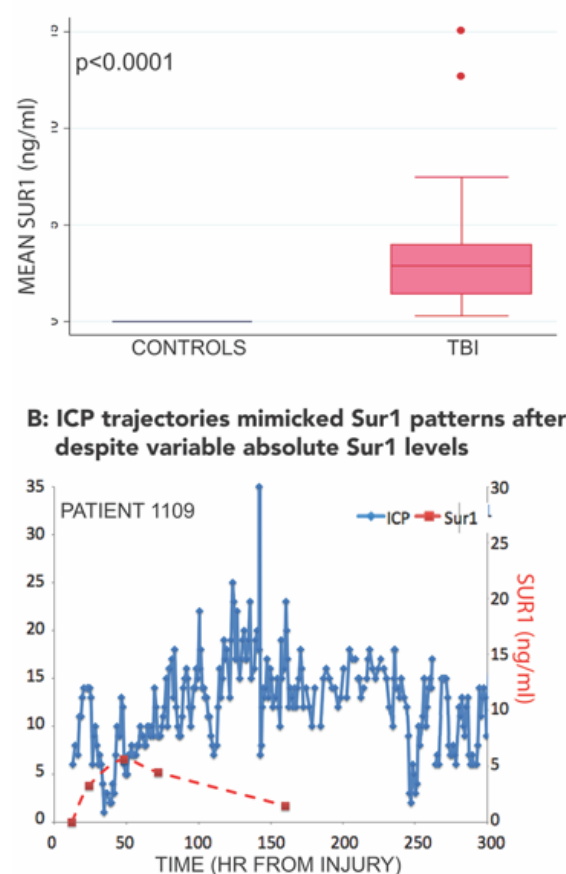

C: No correlation between mean Sur1 level and initial glasgow coma scale score on admission

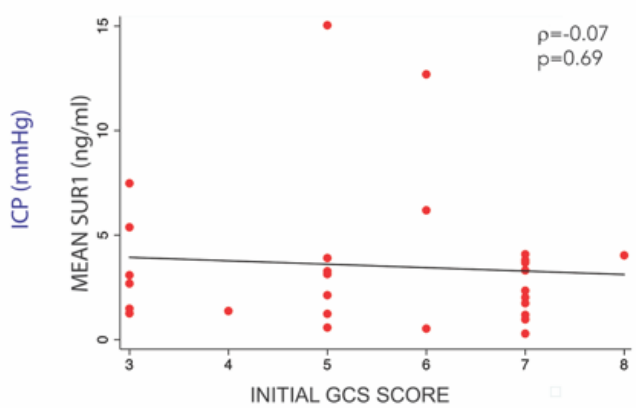

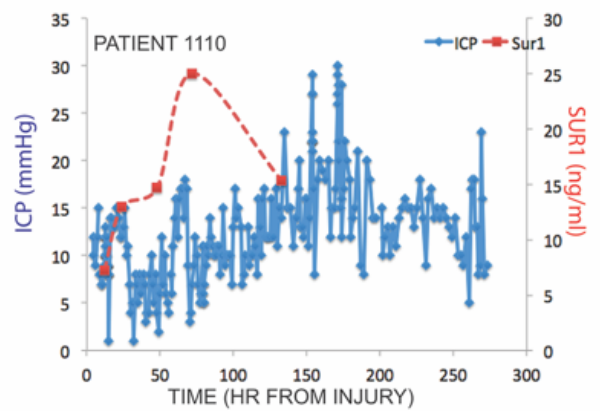

Figure 4. Cerebrospinal fluid SUR1 levels may be a biomarker for secondary injury after traumatic brain injury. (A) Box plot demonstrating increased cerebrospinal fluid (CSF) SUR1 levels (ng/mL) in TBI (red) vs. absent in controls. Error bars represent inter-quartile range. Adapted with permission from Jha et al., Sulfonylurea Receptor 1: A Novel Biomarker for Cerebral Edema in Severe Traumatic Brain Injury, Crit Care Med, 45 (3), e255-e264, 2017. (B) Temporal graph of SUR1 levels (ng/ml, red line) and intracranial pressure (ICP mmHg, blue line) in two patient examples (\#1109, \#1110). Here, the ICP trajectory mimics the SUR1 pattern after a variable temporal delay. Adapted with permission from Jha et al., Sulfonylurea Receptor 1: A Novel Biomarker for Cerebral Edema in Severe Traumatic Brain Injury, Crit Care Med, 45 (3), e255-e264, 2017. (C) Scatter plot demonstrating no correlation between mean Sur1 level (red dots) and initial Glasgow coma scale score ( $x$-axis) on admission. Trendline shown in black. Pearson's rho $=0.07, p=0.69$. 

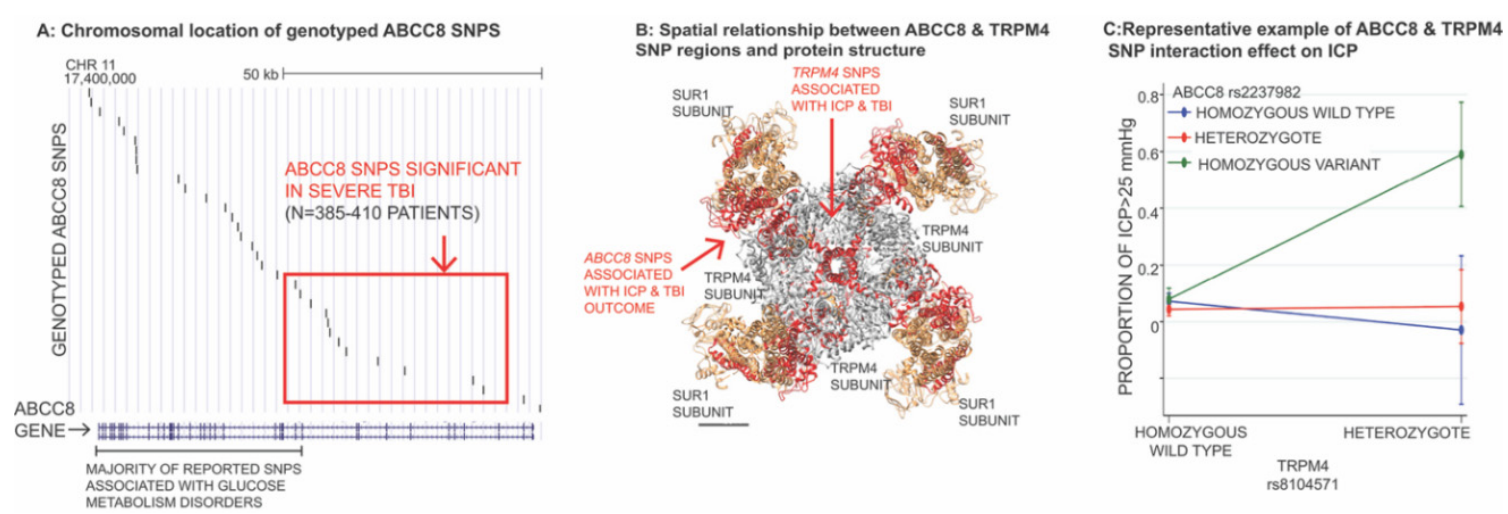

Figure 5. ABCC 8 and TRPM4 genetic variation may impact edema, intracranial hypertension, and outcome post-TBI. (A) Chromosomal location of genotyped $A B C C 8$ single nucleotide polymorphisms (SNPs). Graphical display of the chromosomal location of sequenced (black lines) vs. significant (red box) SNPs as plotted on the UCSC genome browser (version GRCh38/hg38). The $A B C C 8$ gene is shown in blue, with vertical lines representing individual exons (and the interspersed horizontal lines representing introns) All the significant SNPs identified in TBI are upstream (introns 2-15) whereas the majority of SNPs significant in disorders of glucose metabolism (annotated in black) are downstream. Scale bar of $50 \mathrm{~kb}$ is shown. Adapted with permission from Jha et al., 2018. (B) Spatial relationship between $A B C C 8$ and TRPM4 SNP regions and protein structure. This three-dimensional structure was created from UCSF Chimera automated software, combining the known crystallized structure of SUR1 (Li et al., obtained from the Research Collaboratory for Structural Bioinformatics Protein Data Bank [RCSB-PDB] using the ID 5WUA), with TRPM4 (Autzen et al., obtained from the RCSB-PDB using the ID 6BQV). In the putative octameric structure, the four SUR1 subunits are brown and the four TRPM4 subunits are gray. Amino acid sequences highlighted in red are those encoded by regions of TRPM4 DNA (in proximity to rs8104571 and rs150391806), and those encoded by DNA regions in linkage disequilibrium with the eight significant $A B C C 8$ SNPs in TBI. (C) Representative example of $A B C C 8$ and TRPM4 SNP interaction effect on ICP. This graph demonstrates the direction and magnitude of the interaction effect on ICP between TRPM4 rs8104571 and ABCC8 rs2237982. Here, patients homozygous wild-type for TRPM4 rs8104571 have almost no proportion of their ICP measurements recorded at $>25 \mathrm{mmHg}$ regardless of their $A B C C 8 \mathrm{rs} 2237982$ genotype. This is also true for patients heterozygous for TRPM4 rs8104571 who are also wild-type for $A B C C 8$ rs2287982 (blue). Those who are heterozygous for TRPM4 rs8104571 and are also heterozygous for ABCC8 rs2287982 SNPs (red) have an average of $\sim 5 \%$ of their ICP measurements recorded at $>25 \mathrm{mmHg}$. However, patients who are both heterozygous for TRPM4 rs8104571 and homozygous-variant for ABCC8 rs2237982, have an average of $\sim 60 \%$ of their ICP measurements recorded at $>25 \mathrm{mmHg}$. Similar interaction effects between TRPM4 rs8104571 and all three significant $A B C C 8$ SNPs in intron 10 (not shown) were obtained for multiple measures of ICP (including peak, average ICP values). Adapted with permission from Jha et al., 2018.

Two TRPM4 SNPs were associated with intracranial hypertension after TBI: rs8104571 and rs150391806. Effect sizes were large (e.g., 7-10 mmHg average ICP, 20-29 mmHg peak ICP with presence of the variant SNP), and they withstood corrections for multiple comparisons [124]. These were both rare variants with minor allele frequencies of 1\% and 0.4\%, respectively. Rs150391806 in exon 24 is a missense mutation. These two SNPs also demonstrated regional clustering (downstream) between intron 20 and exon 24 of the 25 exon TRPM4 gene corresponding to regions of DNA that encode the TRPM4 channel pore and SUR1-TRPM4 binding interface (Figure 5B). However, as with $A B C C 8$, the true functional impact of these variants is currently unknown. Of note, rs150391806 has also been associated with cardiac conduction disorders, including progressive familial heart block and Brugada syndrome [124].

A significant interaction effect has been reported between rs8104571 and three of the significant ABCC8 SNPs, all located in intron-10 (rs2237982, rs2293261, rs11024286), that influences intracranial hypertension [124]. A representative example of this interaction is illustrated in Figure 5C, where 
patients heterozygous for TRPM4 rs8104571 and homozygous-variant for ABCC8 rs2237982 have $\sim 60 \%$ of their ICP measurements $>25 \mathrm{mmHg}$ vs. $\sim 0-5 \%$ in rs 2237982 homozygous-wild types or heterozygotes. Those homozygous for TRPM4 $\mathrm{rs} 8104571$ had almost no ICP recordings $>25 \mathrm{mmHg}$, regardless of their $A B C C 8$ rs2237982 genotype. This interaction effect was consistent across multiple measures of ICP where average ICP was $\sim 30 \mathrm{mmHg}$ vs. $\sim 10 \mathrm{mmHg}$ and peak ICP was $\sim 60 \mathrm{mmHg}$ vs. $\sim 20-30 \mathrm{mmHg}$ [124]. Virtually identical findings were reported for TRPM4 rs8104571 interactions with all three of the intron-10 ABCC8 SNPs across the different measures of ICP [124].

AQP4 genetic variation may also be relevant to cerebral edema pathophysiology related to SUR1-TRPM4. The role AQP4 in post-TBI edema generation is complex and multifaceted: AQP4 on perivascular foot processes is involved in increased intracellular water movement and cellular swelling, whereas decreased AQP4 expression on subpial, subependymal, and glymphatic surfaces reduces water elimination [14]. As mentioned earlier, SUR1-TRPM4 has been reported to co-assemble with AQP4 to form hetero-multimeric complexes mediating water influx and oncotic edema; this has not specifically been studied in models of brain contusion, but has been demonstrated in astrocytes after cold-injury to the cerebellum [55]. Interactions between genetic variations in all three protein structures may thus have major implications regarding edema formation. Previous candidate-gene research has demonstrated that polymorphisms in the AQP4 gene are related to outcome after TBI [116], but has not evaluated effects on measures of cerebral edema [125]. Nonetheless, AQP4 variants and mutations (including gain of function polymorphisms) have been reported to influence water permeability of cell membranes [126]. In ICH, AQP4 variant rs 1054827 has been associated with perihematomal edema formation in a small sample of 128 patients [127].

Small sample sizes in TBI (particularly severe injury) have precluded unbiased genome wide association studies (GWAS) to identify novel genetic targets or validate the above findings. Despite 5 years and 11 enrolling sites, there are $<300$ patients with severe TBI in TRACK-TBI with genetic material available for evaluation. Efforts to increase sample sizes for genetic evaluation in TBI and validate these findings are paramount. These initiatives are currently ongoing in a large international multi-center collaboration known as GAIN (Genetic Associations in Neurotrauma) combining cohorts from TRACK-TBI (North America) and CENTER-TBI (Europe). Nonetheless, the reported findings are provocative, promising and consistent with known SUR1-TRPM4 pathophysiology. They support the theory that $A B C C 8$ and TRPM4 genetic variation may play a role in cerebral edema development, intracranial hypertension and outcome after TBI. The spatial clustering of significant SNPs around critical regions of DNA encoding sequences contained in the channel pore, sulfonylurea receptor, and SUR1-TRPM4 binding interface, and the interaction effect between ABCC 8 and TRPM4 variants moderating ICP adds further credence to this hypothesis. Validating effects of genetic variability in this pathway may facilitate risk stratification, prognostication, and guide patient selection for future trials.

\subsection{Preclinical Studies of SUR1 Inhibition in TBI}

A growing body of research in preclinical TBI has consistently demonstrated benefit of GLI on multiple post-traumatic outcome measures, including cerebral edema, BBB integrity, contusion expansion, and cognitive and motor function (Table 2) [50,60,61,82-85,101,128,129]. While GLI may improve motor and cognitive outcomes in models like FPI [128], and possibly cranial blast injury [101], the preponderance of preclinical evidence available to date suggests that its greatest value lies in treating contusions $[50,60,61,82,83,85,129,130]$. 
Table 2. Preclinical Studies of Glibenclamide in TBI (Chronologically Listed).

\begin{tabular}{|c|c|c|c|c|}
\hline Authors, Year & Study Title & TBI Model & GLI Dose & Results \\
\hline Simard et al, 2009 [61] & $\begin{array}{l}\text { Key Role of Sulfonylurea } \\
\text { Receptor } 1 \text { in Progressive } \\
\text { Secondary Hemorrhage after } \\
\text { Brain Contusion }\end{array}$ & $\begin{array}{l}\text { Rat Focal Cortical Contusion } \\
\text { - } \quad 4.5 \mathrm{~mm} \text { impactor } \\
\text { - } \quad 10 \mathrm{~g} \text { weight drop } \\
\text { - } \quad 5 \mathrm{~cm} \text { distance } \\
\text { - } \quad 1 \mathrm{~m} / \mathrm{s} \text { impact velocity }\end{array}$ & $\begin{array}{l}\text { - } \quad \text { Loading: } 10 \mu \mathrm{g} / \mathrm{kg} \mathrm{IP} \\
\text { - } \quad \text { Maintenance: } 200 \mathrm{ng} / \mathrm{h}\end{array}$ & $\begin{array}{ll}\text { - } & \text { SUR1 upregulation } 3 \mathrm{~h} \text { (capillaries), } 24 \mathrm{~h} \\
\text { (neurons, capillaries) } \\
\text { - } \quad \text { Vehicle blood extravasation (contusion expansion, } \\
\text { double by } 12 \mathrm{~h} \text { ) }>\text { GLI group (minimal expansion) at } 6 \mathrm{~h} \text {, } \\
12 \mathrm{~h}, 24 \mathrm{~h} \\
\text { - } \quad \downarrow 24 \mathrm{~h} \text { histological lesion volume in GLI vs. vehicle } \\
\text { - } \quad \begin{array}{l}\text { Improved outcome (spontaneous vertical exploration) } \\
\text { with GLI }\end{array}\end{array}$ \\
\hline Patel et al., 2010 [60] & $\begin{array}{l}\text { GLI Reduces Hippocampal Injury } \\
\text { and Preserves Rapid Spatial } \\
\text { Learning in a Model of TBI }\end{array}$ & $\begin{array}{l}\text { Rat Cortical Impact Injury } \\
\text { - } \quad \text { Modified Feeney Device } \\
\text { - } \quad 10 \mathrm{~g} \text { weight drop } \\
\text { - } \quad 3 \mathrm{~cm} \text { distance } \\
\text { - } \quad 0.77 \mathrm{~m} / \mathrm{s} \text { impact velocity }\end{array}$ & $\begin{array}{l}\text { - } \quad \text { Loading: } 10 \mu \mathrm{g} / \mathrm{kg} \mathrm{IP} \\
\text { Maintenance: } 200 \mathrm{ng} / \mathrm{h} \\
\text { X 7d }\end{array}$ & $\begin{array}{ll}\text { - } & \text { Hippocampal SUR1 upregulation } 6 \mathrm{~h} \text {, peak } 12 \mathrm{~h} \\
\text { - } & \downarrow \text { hippocampal caspase-3 labeling with GLI } \\
\text { - } & \text { Improved memory retention (hidden platform trial) with } \\
& \text { GLI treatment } \\
\text { - } & 3 X \text { reduction in FJC+ hilar cell death with GLI treatment } \\
\end{array}$ \\
\hline $\begin{array}{l}\text { Zweckberger et al., } \\
2014 \text { [82] }\end{array}$ & $\begin{array}{l}\text { GLI Reduces Secondary Brain } \\
\text { Damage After Experimental TBI }\end{array}$ & $\begin{array}{l}\text { Rat CCI } \\
\text { - } \quad 5 \mathrm{~mm} \text { impactor } \\
\text { - } \quad 1.5 \mathrm{~mm} \text { depth } \\
\text { - } \quad 7.5 \mathrm{~m} / \mathrm{s} \text { impact velocity } \\
\text { - } \quad 300 \mathrm{~ms} \text { impact duration }\end{array}$ & $\begin{array}{l}\text { - } \quad \text { Loading: } 10 \mu \mathrm{g} / \mathrm{kg} \mathrm{IP} \\
\text { - Maintenance: } 200 \mathrm{ng} / \mathrm{h}\end{array}$ & $\begin{array}{l}\text { - GLI did not improve intracranial pressure, cerebral } \\
\text { microdialysis parameters, seizures, or motor function } \\
\text { (beam walk) } \\
\text { - } \quad \text { GLI reduced } 24 \mathrm{~h} \text { brain water content (ipsilateral) by } \\
\text { - } 15.3 \% \\
\text { GLI reduced contusion volume at } 8,24,72 \mathrm{~h} \text { and } 7 \mathrm{~d}\end{array}$ \\
\hline Xu et al., 2016 [83] & $\begin{array}{l}\text { GLI Attenuates Blood Brain } \\
\text { Barrier Disruption in Adult Mice } \\
\text { after TBI }\end{array}$ & $\begin{array}{l}\text { Mouse CCI } \\
\text { - } \quad 3 \mathrm{~mm} \text { impactor } \\
\text { - } \quad 1.5 \mathrm{~mm} \text { depth } \\
\text { - } \quad 1.5 \mathrm{~m} / \mathrm{s} \text { impact velocity }\end{array}$ & - $10 \mu \mathrm{g} /$ day X 3 days & $\begin{array}{l}\text { - } \quad \text { GLI reduced } 72 \mathrm{~h} \text { ipsilateral brain water by } 51.6 \% \\
\text { - } \quad \text { GLI reduced BBB disruption } \\
\text { GLI inhibited loss of ZO-1 and reduced early stage } \\
\text { apoptosis induced by stretch injury }\end{array}$ \\
\hline Stokum et al., 2017 [101] & $\begin{array}{l}\text { GLI Pretreatment Protects } \\
\text { Against Chronic Memory } \\
\text { Dysfunction and Glial Activation } \\
\text { in Rat Cranial Blast TBI }\end{array}$ & $\begin{array}{l}\text { Rat Direct Cranial Blast TBI } \\
\text { - } \quad 0.22 \text { caliber cartridge } \\
\text { - } \quad \text { Peak pressure } \sim 427 \mathrm{kPA} \\
\text { - } \quad 25.4 \mathrm{~mm} \text { blast wave }\end{array}$ & $\begin{array}{l}\text { - } \quad \text { Loading: } 10 \mu \mathrm{g} / \mathrm{kg} \mathrm{IP} \\
\text { Maintenance: } 200 \mathrm{ng} / \mathrm{h} \\
\text { X 7d }\end{array}$ & $\begin{array}{l}\text { - } \quad \text { GLI did not improve transient } \\
\text { neurobehavioral/vestibulomotor deficits } \\
\text { - } \quad \text { GLI pretreatment improved hippocampal } \\
\text { memory function } \\
\text { - } \quad \text { GLI pretreatment improved chronic } \\
\text { hippocampal neuroinflammation }\end{array}$ \\
\hline
\end{tabular}


Table 2. Cont.

\begin{tabular}{|c|c|c|c|c|}
\hline Authors, Year & Study Title & TBI Model & GLI Dose & Results \\
\hline Jha et al., 2018 [84] & $\begin{array}{l}\text { GLI Produces Region Dependent } \\
\text { Effects on Cerebral Edema in a } \\
\text { Combined Injury Model of TBI } \\
\text { and Hemorrhagic Shock in Mice }\end{array}$ & $\begin{array}{l}\text { Mouse CCI } \\
\text { - } \quad 1 \mathrm{~mm} \text { depth } \\
\text { - } \quad 5 \mathrm{~m} / \mathrm{s} \text { impact velocity } \\
\pm \text { Hemorrhagic shock (HS) } \\
\text { - } \quad \text { MAP } 25-27 \mathrm{mmHg} X \\
\quad 20 \mathrm{~min}\end{array}$ & $\begin{array}{l}\text { - } \quad \text { Loading: } 20 \mu \mathrm{g} / \mathrm{kg} \mathrm{IP} \\
\text { - Maintenance: } 400 \mathrm{ng} / \mathrm{h}\end{array}$ & $\begin{array}{l}\text { - GLI did not improve } 24 \mathrm{~h} \text { ipsilateral brain water in CCI } \\
\text { or CCI+HS } \\
\text { GLI reduced contralateral brain water to sham levels } \\
\text { after CCI+HS (no contralateral edema developed in } \\
\text { CCI alone) } \\
\text { - GLI had no effect on } 72 \mathrm{~h} \text { ipsilateral brain water in } \\
\text { CCI+HS, contralateral edema had resolved by } \\
\text { this time-point. }\end{array}$ \\
\hline $\begin{array}{l}\text { Gerzanich et al., } \\
2019[50]\end{array}$ & $\begin{array}{l}\text { SUR1, TRPM4 and KIR6.2 Role in } \\
\text { Hemorrhagic Progression of } \\
\text { Contusion }\end{array}$ & $\begin{array}{l}\text { Rat CCI } \\
\text { - } \quad 5 \mathrm{~mm} \text { impactor } \\
\text { - } \quad 4.5 \mathrm{~mm} \text { depth } \\
\text { - } \quad 1 \mathrm{~m} / \mathrm{s} \text { impact velocity } \\
\text { - } \quad 200 \mathrm{~ms} \text { impact duration }\end{array}$ & $\begin{array}{l}\text { - } \quad \text { Loading: } 10 \mu \mathrm{gg} / \mathrm{kg} \mathrm{IP} \\
\text { - } \quad \text { Maintenance: } 400 \mathrm{ng} / \mathrm{h}\end{array}$ & $\begin{array}{l}\text { - } \quad \downarrow \text { GLI hemorrhagic progression of contusion by } 58 \% \\
\quad \downarrow \text { GLI mean swelling by } \sim 66 \%\end{array}$ \\
\hline $\begin{array}{l}\text { Bramlett et al [128] } \\
\text { Deng-Bryant et al Jha et } \\
\text { al., (abstracts 2015), [129] } \\
\text { Jha et al (in preparation) }\end{array}$ & $\begin{array}{l}\text { Operation Brain Trauma Therapy: } \\
\text { GLI Treatment in TBI }\end{array}$ & $\begin{array}{l}\text { Rat CCI } \\
\text { Rat FPI I, } 1.8-2.1 \mathrm{~atm}) \\
\text { Rat PBBI }\end{array}$ & $\begin{array}{l}\text { - } \quad \text { Loading: } 10 \mu \mathrm{g} / \mathrm{kg} \mathrm{IP} \\
\text { Maintenance: } 200 \mathrm{ng} / \mathrm{h} \\
\text { X7d }\end{array}$ & $\begin{array}{ll}\text { - } & \text { GLI improved motor function (beam balance, walk) } \\
\text { - } & \text { GLter CCI } \\
\text { - } & \text { GLI reduced 21d contusion volume after CCI } \\
\text { - } & \text { GLI did not improve motor, cognitive, or histopathologic } \\
& \text { outcome after PBBI }\end{array}$ \\
\hline
\end{tabular}

$\mathrm{BBB}=$ blood brain barrier; $\mathrm{CCI}$ = controlled cortical impact, FJC = Fluoro Jade-C; FPI = fluid percussion injury; GLI = glibenclamide; PBBI = penetrating ballistic-like brain injury; SUR1 = sulfonylurea receptor 1 ; TBI = traumatic brain injury; ZO- $1=$ zona occludens- $1 ; \downarrow=$ decrease. 
In different models, severities, and species of contusional TBI, GLI has improved BBB integrity and markedly reduced hemorrhage progression at multiple time points ranging from 45 min to $7 \mathrm{~d}[50,67,82,83]$. In both mouse and rat CCI models (from two independent laboratories), extravasated blood from a leaky BBB at $24 \mathrm{~h}$ was approximately two fold greater in vehicle animals vs. those treated with GLI $[61,83]$. This difference with GLI treatment was notable by $3 \mathrm{~h}$, became significant by $6 \mathrm{~h}$ post-injury, peaked at $12 \mathrm{~h}$ after which it stabilized by $24 \mathrm{~h}$ (Figure 3C) [61]. Reduced BBB leakiness was accompanied by reduced loss of ZO-1 and occludin in endothelial cells [83]. It should be noted that GLI-treated animals had minimal extravasated blood, and the amount quantified at $24 \mathrm{~h}$ was no different than that at $45 \mathrm{~min}$, suggesting minimal progression of BBB breakdown with treatment [61]. Antisense oligodeoxynucleotide against SUR1 produced similar results in this study [61]. Not surprisingly, likely as a result of limited BBB breakdown, hemorrhagic progression of contusion by $24 \mathrm{~h}$ was reduced by $\sim 58 \%$ [50]. Antisense oligodeoxynucleotides against Abcc8/SUR1 and Trpm4/TRPM4 but not Kcjn11/Kir6.2 reduced both hemorrhage progression and hemispheric swelling vs. controls after CCI [50]. Quantification of contusion volume over 7d of GLI treatment has demonstrated consistently lower volumes $(\sim 30-40 \%)$ at all time points $(3 \mathrm{~h}, 24 \mathrm{~h}, 72 \mathrm{~h}, 7 \mathrm{~d}$; all $p<0.01)$ [82]. GLI has also been tested by the rigorous, blinded, multi-center Operation Brain Trauma Therapy (OBTT) consortium, which evaluates promising therapies in three standardized preclinical models of TBI, including CCI [131]. Most drugs tested by OBTT performed "below or well below expectations based on the published literature" [132]. Although results from OBTT are pending publication for GLI, preliminary reports support a significant benefit in contusion volume reduction $[85,130]$. GLI has been identified by OBTT as the second highest scoring drug in the consortium (after levetiracetam), and the only agent tested by the consortium to reduce contusion/lesion volume in CCI [130].

GLI significantly decreases cerebral edema $24 \mathrm{~h}$ after CCI $[50,82,83]$. In two of the three studies, there was a $52-66 \%$ reduction in ipsilateral hemispheric swelling $[50,83]$. GLI also reduces diffuse (contralateral) edema exacerbated by detrimental second insults such as hypotension [84]. Most studies evaluating effects of GLI on post-traumatic cerebral edema have used percent brain water (\%BW) for quantification. While this is considered the gold standard measure, it is biased against detection of cellular edema. In order to detect increases in \%BW, some degree of vasogenic edema/BBB breakdown and perfusion is required; isolated cellular swelling in the absence of this is merely redistribution of water from the interstitial to intracellular space without actually increasing total water content [15]. MRI endophenotyping of edema may be valuable to evaluate such granular effects of SUR1-TRPM4 blockade. Pilot data from a combined injury mouse model of CCI plus hypotension indicate reduction of T2 hyperintensity and volume (measuring vasogenic edema) after treatment with GLI [129]. This was noted as early as $3 \mathrm{~h}$ post injury in some mice, and statistically significant at $24 \mathrm{~h}$. GLI effects on cellular swelling measured by mean diffusivity are currently unknown in preclinical models, but MRI based outcome measures may facilitate quantification of cytotoxic edema. Thus, although results of GLI on cerebral edema as measured by \%BW are promising, this method may underestimate potential benefits of SUR1-TRPM4 blockade on cellular swelling, e.g., in astrocytes. In a model of FPI, TRPM4+ astrocytes had double the soma size of TRPM4- astrocytes after injury, as assessed by confocal and electron microscopy. While an important methodology for evaluating preclinical benefit on cellular edema and proof-of-concept, microscopy-based techniques are less clinically translatable than radiographic metrics.

Upregulation of SUR1-TRPM4 in endothelial cells as early as $3 \mathrm{~h}$ (peaking before $24 \mathrm{~h}$ ) coincides with the timing of the GLI benefit on vasogenic edema, BBB breakdown, and contusion expansion after preclinical contusional TBI. Based on this pathophysiology, early treatment with GLI is likely imperative to maximize therapeutic benefit on this process. Given delayed SUR1-TRPM4 upregulation in astrocytes and microglia/macrophages relative to endothelial cells, it is possible that continued treatment with GLI may influence late edema formation and/or neuroinflammation and repair. However, this hypothesis requires further investigation, particularly given the unknown implications of concurrent SUR1-KIR6.2 expression in some cell-types. 


\subsection{Clinical Studies of GLI in TBI}

Three small clinical trials evaluating GLI in TBI have been published (Table 3). Two of these studies, conducted in Iran, explored effects of oral GLI in different subtypes of TBI, including contusion-TBI and diffuse axonal injury(DAI)/traumatic microhemorrhages.

Zafardoost et al., randomized 40 patients with moderate-severe DAI to $1.25 \mathrm{mg}$ oral GLI every $12 \mathrm{~h}$ (this dose was increased to $2.5 \mathrm{mg}$ if no hypoglycemia was noted at the lower dose) vs. control (no placebo) [133]. Power calculations were designed to detect an effect size of Cohen's $d \geq 0.7$ with $\alpha=0.05$ and $1-\beta=0.80$ in this sample size. The distribution of presenting GCS scores between treatment vs. control groups is not clearly presented (although reported to not be significantly different). Outcome was assessed at 1 week and at discharge using ordinal measures of GCS and the Glasgow outcome scale (GOS) score, all of which were significantly better in the treated group vs. control (all $p \leq 0.004$ ). Long term functional outcomes were not evaluated.

A blinded placebo-controlled randomized trial of oral GLI in contusion-TBI was performed by Khalili et al. in 66 patients with moderate-severe TBI (GCS 5-12) [134]. Multiple outcome measures were obtained, including contusion volumes (initial, day-3, day-7), and 3-month ordinal functional outcome metrics, including GOS, modified Rankin Scale, and disability rating scale. To have $80 \%$ power at an $\alpha=0.05$, a sample size of 60 was required to detect a $5 \%$ difference in outcomes. Patients were randomized to placebo or $10 \mathrm{mg}$ oral GLI for 10 days. No differences were noted in any of the functional outcome measures or absolute contusion volumes. Patients treated with GLI had significantly lower contusion expansion ratios between both baseline-day3 $(p<0.001)$, and baseline-day $7(p<0.003)$.

Although pharmacokinetic values were not reported in the studies by Zafardoost et al., or Khalili et al., intermittent oral GLI dosing can be problematic, with sharp supratherapeutic peaks (risking hypoglycemia) and prolonged subtherapeutic troughs [36]. Variability in stomach $\mathrm{pH}$ can further influence plasma levels of the drug [36,94]. A small Phase-2 multi-center randomized trial reported by Eisenberg et al., utilized an intravenous formulation of GLI, currently known as BIIB093 [135]. This drug has also been used in a published Phase- 2 trial in large hemispheric infarction (LHI) and is being evaluated in an ongoing Phase- 3 trial of LHI (NCT02864953) as well as a large Phase-2 contusion-TBI trial (NCT03954041) [91,135]. The intravenous formulation enables rapid and stable plasma levels, reducing the risk of hypoglycemia and maximizing therapeutic duration.

The radiographic findings by Eisenberg et al. (with BIIB093) are similar to those reported by Khalili et al., in contusion [135]. Here, 28 patients (GCS 4-14) were randomized within $10 \mathrm{~h}$ of TBI to a $72 \mathrm{~h}$ infusion of placebo or BIIB093. Of these, only 14 patients had contusional TBI. Primary outcome was MRI-defined edema and or hemorrhage on a 1.5T scanner at $72 \pm 12 \mathrm{~h}$. GOS-extended at 90 days was a pre-specified secondary outcome. Analysis of contusions (7/group) revealed a 1036\% increase in lesion volume (hemorrhage plus edema) in placebo vs. $136 \%$ in controls; this tenfold difference was not significant $(p=0.15)$, likely due to small sample size and contusion heterogeneity. It should also be noted that baseline contusion volumes were much higher in the treatment group of this study. Hemorrhage volumes decreased $29.6 \%$ with BIIB093 vs. an $11.6 \%$ increase with placebo; however, this was not significant. Nonetheless, one may speculate that the pathophysiologic basis for this relates to GLI enhanced RBC phagocytosis by macrophages (Simard et al., [136]). MRI measures of edema in this study included mean diffusivity (MD) as a proxy for overall water diffusivity, free water (FW) as a proxy for extracellular water, and tissue $\mathrm{MD}(\mathrm{MDt})$ as a proxy for intracellular water. These measures were compared in lesions vs. uninjured white matter (WM). Untreated lesions had increased edema by all three measures vs. uninjured WM $(p<0.02)$. In BIIB093 treated patients, there was no difference in any of these measures vs. uninjured WM. There was no improvement in 90-day functional outcome with BIIB093 vs. placebo in this small cohort; however, the study was not powered for this metric. 
Table 3. Clinical Studies of Glibenclamide in TBI (Chronologically Listed).

\begin{tabular}{|c|c|c|c|c|}
\hline Authors, Year & Study Title & Study Design & Sample Size & Outcome \\
\hline $\begin{array}{l}\text { Zafardoost et al., } \\
2016 \text { [133] }\end{array}$ & $\begin{array}{l}\text { Evaluation of the Effect of } \\
\text { Glibenclamide in Patients with DAI } \\
\text { Due to Moderate to Severe Head } \\
\text { Trauma }\end{array}$ & $\begin{array}{l}\text { Randomized Controlled Trial } \\
\text { - } \quad \text { DAI, GCS } \leq 12 \\
\text { - } \quad \text { Dose: } 1.25 \mathrm{mg} \text { oral GLI Q12H } \\
\text { (2.5 mg Q12H if no hypoglycemia) } \\
\text { - } \quad \text { Duration: } 7 \text { days or ICU discharge }\end{array}$ & $\mathrm{N}=40$ & $\begin{array}{l}\text { - } \text { GLI was associated with better GCS score } 1 \text { week } \\
\text { - } \quad \text { GLI was associated with a better GOS score at } \\
\text { discharge }(p=0.001) \\
\text { - } \text { GLI was associated with shorter hospital length of stay } \\
(p=0.03)\end{array}$ \\
\hline $\begin{array}{l}\text { Khalili et al., } \\
2017 \text { [134] }\end{array}$ & $\begin{array}{l}\text { Effects of Oral Glibenclamide on } \\
\text { Brain Contusion Volume and } \\
\text { Functional Outcome of Patients with } \\
\text { Moderate and Severe TBI: } \\
\text { A Randomized Double Blind Placebo } \\
\text { Controlled Clinical Trial }\end{array}$ & $\begin{array}{l}\text { Double-Blind Randomized } \\
\text { Controlled Trial } \\
\text { - } \quad \text { Moderate-Severe TBI (GCS 5-12) } \\
\text { - } \quad \text { Dose: } 10 \mathrm{mg} \text { /day oral GLI } \\
\text { - } \quad \text { Duration: } 10 \text { days }\end{array}$ & $N=66$ & $\begin{array}{l}\text { - } \quad \text { No difference in contusion volume between GLI vs } \\
\text { vehicle at baseline, day } 3 \text { and day } 7 \\
\text { - GLI reduced contusion volume expansion ratio } \\
\text { between day } 1 \text { vs. } 3(p<0.001) \text { and day } 1 \text { vs. } 7 \\
\text { - } p=0.003) \\
\text { GLI did not improve functional outcome at } 3 \text { months } \\
\text { as measured by GOS, MRS or DRS }\end{array}$ \\
\hline $\begin{array}{l}\text { Eisenberg et al., } \\
2019 \text { [135] }\end{array}$ & $\begin{array}{l}\text { Magnetic Resonance Imaging Pilot } \\
\text { Study of Intravenous Glyburide } \\
\text { in TBI }\end{array}$ & $\begin{array}{l}\text { Phase-2 Randomized Controlled Trial } \\
\text { - } \quad \text { Dose: IV } 0.13 \mathrm{mg} \text { load over } 2 \mathrm{~min}, \\
0.16 \mathrm{mg} / \mathrm{h} \text { for } 6 \mathrm{~h}, 0.11 \mathrm{mg} / \mathrm{h} \text { for } \\
66 \mathrm{~h} \\
\text { - Duration: } 3 \text { days }\end{array}$ & $\begin{array}{l}\mathrm{N}=28(\mathrm{~N}=14 \\
\text { contusion) }\end{array}$ & $\begin{array}{l}\text { - Contusion growth was non-significantly increased } \\
(10 \text { fold) in placebo }(1036 \pm 1963.28 \%) \text { vs. GLI } \\
\text { (136 } \pm 195.62 \% ; p=0.15, \mathrm{n}=7 / \text { group) } \\
\text { MRI measures of edema (FW, MD, MDt) in lesion vs. } \\
\text { uninjured WM were different in placebo }(p<0.02) \text { but } \\
\text { not GLI }\end{array}$ \\
\hline NCT03954041 & $\begin{array}{l}\text { Antagonizing SUR1-TRPM4 To } \\
\text { Reduce the progression of } \\
\text { intracerebral hematoma And edema } \\
\text { surrounding Lesions (ASTRAL) }\end{array}$ & $\begin{array}{l}\text { Multicenter Double-Blind Multidose } \\
\text { Placebo-Controlled Randomized Trial } \\
\text { (Phase-2) } \\
\text { - } \quad \text { Drug Administration: IV } \\
\text { bolus+ infusion } \\
\text { - } \quad \text { Low Dose Arm: } 3 \mathrm{mg} / \text { day } \\
\text { - } \quad \text { High Dose Arm: } 5 \mathrm{mg} / \text { day } \\
\text { - } \quad \text { Duration: } 96 \mathrm{~h}\end{array}$ & $\begin{array}{l}\text { Estimated } \\
\mathrm{N}=160\end{array}$ & - Currently enrolling \\
\hline
\end{tabular}

DAI = Diffuse Axonal Injury; DRS = Disability Rating Scale; FW = free water; GCS = Glasgow Coma Scale; GLI = glibenclamide; GOS = Glasgow Outcome Scale; IV = intravenous; MD = mean diffusivity; $\mathrm{MDt}=$ tissue mean diffusivity; $\mathrm{MRI}=$ magnetic resonance imaging; $\mathrm{MRS}=$ Modified Rankin Scale; $\mathrm{WM}=$ white matter. 
The compelling molecular and preclinical evidence supporting the benefit of GLI, particularly in contusion models, combined with encouraging clinical data and radiographic results in this subcohort despite very small studies, has generated excitement to test this therapy in a larger Phase-2 study of contusion-TBI. ASTRAL is a multicenter, international, double-blind, multidose, placebo-controlled, randomized Phase-2 clinical trial evaluating the safety and efficacy of BIIB093 in supratentorial contusion-TBI (NCT03954041, antagonizing SUR1-TRPM4 to reduce the progression of intracerebral hematoma and edema surrounding lesions). The trial is sponsored by Biogen and is actively enrolling patients. The proposed enrollment is 160 patients across several centers in North America, Europe, and Japan. Two doses will be tested $(3 \mathrm{mg} /$ day and $5 \mathrm{mg} /$ day $\times 96 \mathrm{~h}$ ) with matched placebo groups for each dose. In addition to extremely focused patient selection (contusion-TBI), the ASTRAL trial design leverages the mounting evidence that GLI reduces cerebral edema and hemorrhage progression, and has identified its primary outcome to be contusion expansion by $96 \mathrm{~h}$ (Figure 6). Multiple secondary outcomes will also be obtained, including acute neurological status, functional outcome, and survival. The temporal course of microvascular SUR1-TRPM4 expression and known risk-window for contusion expansion has also informed trial strategy: the treatment window for BIIB093 is thus $6.5 \mathrm{~h}$. This is significantly earlier than $10 \mathrm{~h}$ in the aforementioned BIIB093 trial in TBI reported by Eisenberg et al. [135], as well as the aforementioned ongoing Phase 3 study of BIIB093 in LHI (NCT02864953).

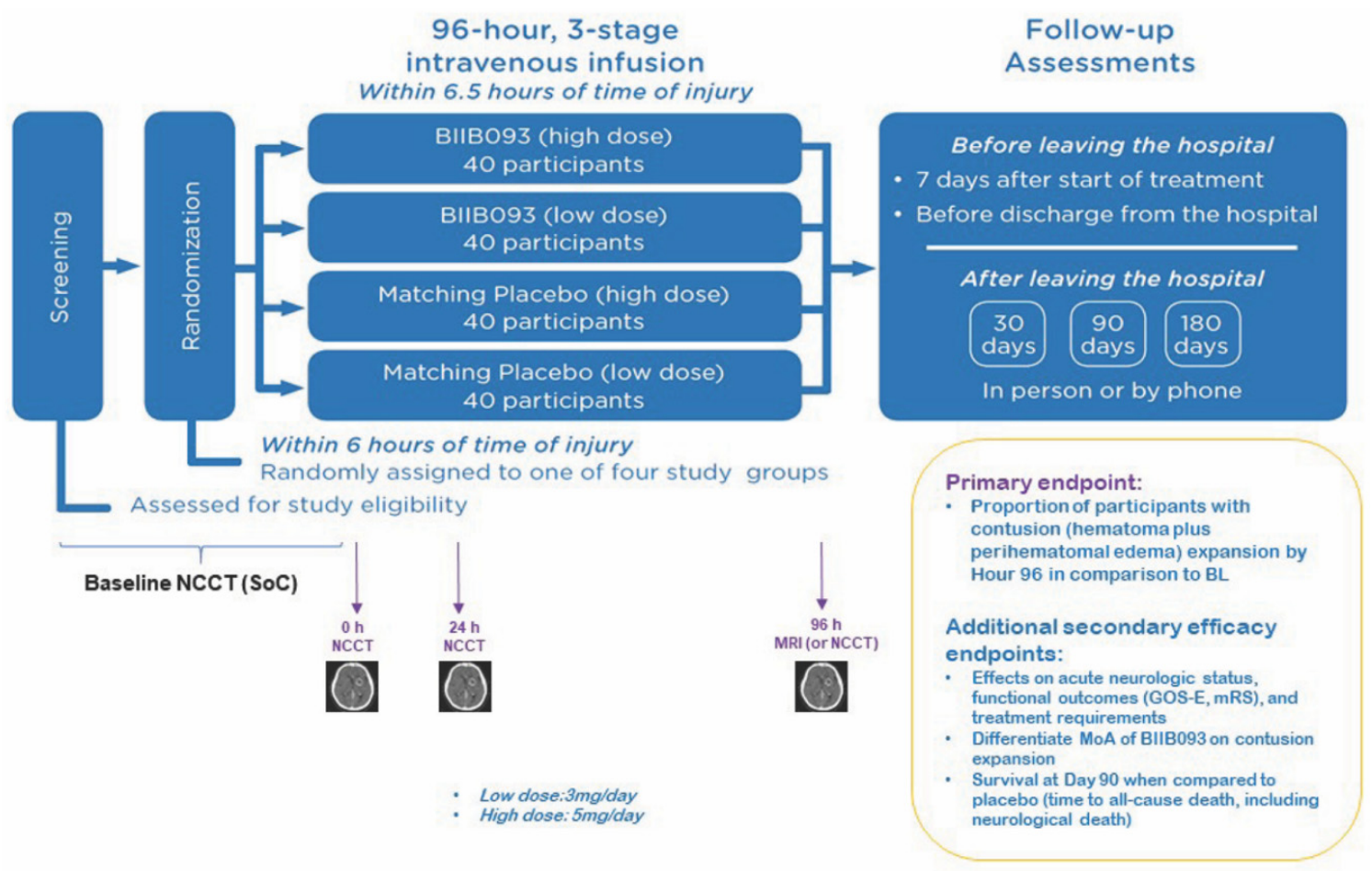

Figure 6. ASTRAL clinical trial design schematic. Diagram outlining the clinical design trial for ASTRAL, a Phase-2 multicenter, international, double-blind, multidose, placebo-controlled, randomized clinical trial evaluating the safety and efficacy of BIIB093 in supratentorial contusion-TBI (NCT03954041, Antagonizing SUR1-TRPM4 to reduce the progression of intracerebral hematoma and edema surrounding lesions). Distribution of participants to high vs. low dose BIIB093 vs. matching placebo is presented; patients are randomized within $6 \mathrm{~h}$ of time of injury. The primary end point is documented by $96 \mathrm{~h}$ MRI or non-contrast CT and related to proportion of participants with contusion expansion vs. baseline. Additional secondary efficacy endpoints will also be obtained as illustrated. Time-points for key follow up assessments are also shown including 7 days after treatment, prior to hospital discharge, 30-day, 90-day, or 180-day evaluations. 


\section{Conclusions}

There is substantial preclinical and clinical evidence supporting a pivotal role of the SUR1-TRPM4 pathway in cerebral edema development, contusion expansion, and outcome after TBI. Consistent findings of benefit with GLI treatment-particularly in contusion across models, injury severity, species, and drug doses-suggests robustness and is encouraging for successful clinical translation. Results from ASTRAL, the ongoing Phase- 2 trial of intravenous GLI (BIIB093) in brain contusion are eagerly awaited. Future research on theragnostic biomarkers and identifying/validating functionally consequential genetic variants in this pathway may eventually inform clinical risk-stratification, prognostication, identification and characterization of treatment-responders, patient selection for precision-medicine based clinical trials, and the development of novel gene-based therapies.

Author Contributions: R.M.J. and J.M.S. were involved in writing the manuscript. J.B., G.C., J.C.H., W.T.K., J.S., R.K.N., and K.N.S. were involved in critical review and editing of the manuscript. All authors have read and agreed to the published version of the manuscript.

Funding: This review article received no external funding.

Acknowledgments: The authors are grateful for funding by the following grants: NIH/NINDS K23NS101036 (R.M.J.), Chuck Noll Foundation award (R.M.J.), University of Pittsburgh School of Medicine Dean's Faculty Advancement Award (R.M.J.). J.M.S. is supported by grants from the Department of Veterans Affairs (I01BX002889), the Department of Defense (SCI170199), the National Heart, Lung and Blood Institute (R01HL082517) and the NINDS (R01NS060801; R01NS102589; R01NS105633). W.T.K. is supported by NIH/NINDS R01NS099209, NIH/NINDS U01NS113443, AHA 17CSA33550004. K.N.S. is supported by NIH/NINDS UO1NS106513, R01NS110721, RO1NR018335, U24NS107215, U24NS107136, and the AHA American Heart Association 17CSA33550004. Industry grants from Biogen, Novartis, Bard, and Hyperfine are also provided to Yale, and K.N.S. serves as 1 of 2 global leads for CHARM.

Conflicts of Interest: R.M.J. provides consulting services for Biogen and is on the advisory board for ASTRAL. J.B. is a paid employee and stockholder of Biogen. J.M.S. holds a US patent $(7,285,574)$, 'A novel non-selective cation channel in neural cells and methods for treating brain swelling.' J.M.S. is a member of the Board of Directors and holds shares in Remedy Pharmaceuticals and is a paid consultant for Biogen. W.T.K. has received research grants and consulting fees from Biogen, and serves on the advisory board for ASTRAL. G.C., J.C.H., J.S., R.K.N., and K.N.S. are on the advisory board for ASTRAL.

\section{Abbreviations}

$\begin{array}{ll}\text { AQP4 } & \text { aquaporin } 4 \\ \text { ATP } & \text { adenosine triphosphate } \\ \text { BAX } & \text { Bcl-associated X protein } \\ \text { BBB } & \text { blood brain barrier } \\ \text { CAMKII } & \text { calmodulin dependent protein kinase-II } \\ \text { CCI } & \text { controlled cortical impact } \\ \text { CNS } & \text { central nervous system } \\ \text { CSF } & \text { cerebrospinal fluid } \\ \text { CT } & \text { computed tomography } \\ \text { DAI } & \text { diffuse axonal injury } \\ \text { FPI } & \text { fluid percussion injury } \\ \text { FRET } & \text { Förster resonance energy transfer } \\ \text { GCS } & \text { Glasgow Coma Scale } \\ \text { GFAP } & \text { glial fibrillary acidic protein } \\ \text { GLI } & \text { glibenclamide } \\ \text { GOS } & \text { Glasgow Outcome Scale } \\ \text { IMPACT } & \text { International Mission for Prognosis and Clinical Trial design in TBI } \\ \text { LHI } & \text { large hemispheric infarction } \\ \text { MMP-9 } & \text { matrix metalloproteinase-9 } \\ \text { MRI } & \text { magnetic resonance imaging } \\ \text { NFAT } & \text { nuclear factor of activated T-cells } \\ \text { NO } & \text { nitric oxide }\end{array}$




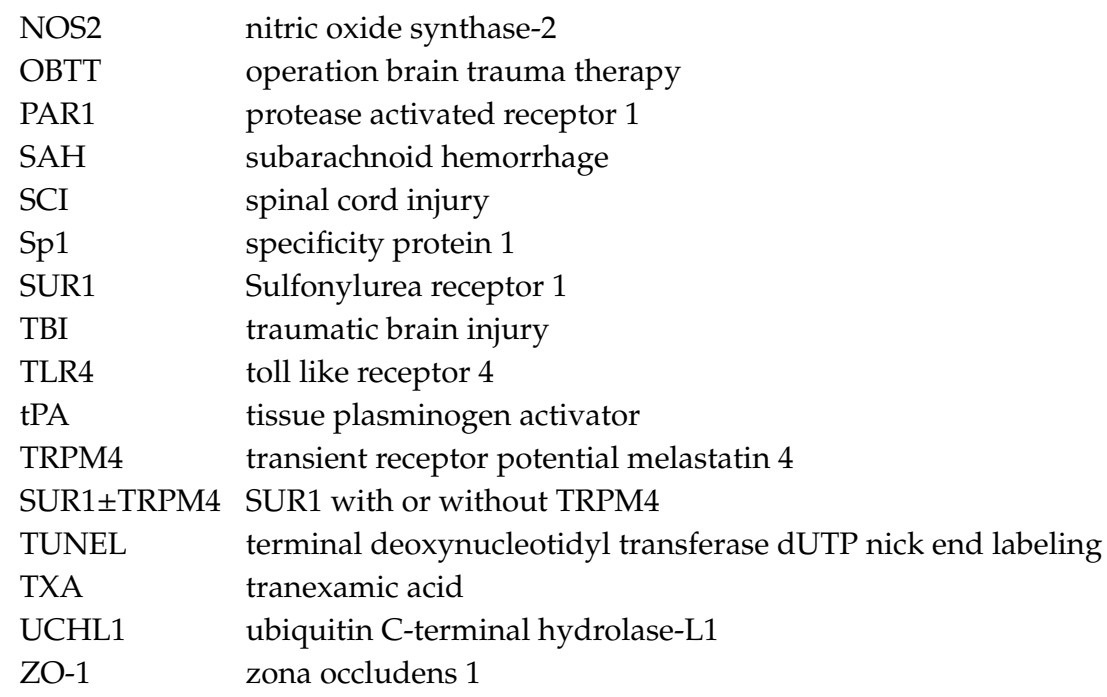

\section{References}

1. Maas, A.I.R.; Menon, D.K.; Adelson, P.D.; Andelic, N.; Bell, M.J.; Belli, A.; Bragge, P.; Brazinova, A.; Büki, A.; Chesnut, R.M.; et al. InTBIR participants and investigators traumatic brain injury: Integrated approaches to improve prevention, clinical care, and research. Lancet Neurol. 2017, 16, 987-1048. [CrossRef]

2. Lingsma, H.F.; Roozenbeek, B.; Steyerberg, E.W.; Murray, G.D.; Maas, A.I.R. Early prognosis in traumatic brain injury: From prophecies to predictions. Lancet Neurol. 2010, 9, 543-554. [CrossRef]

3. Murray, G.D.; Butcher, I.; McHugh, G.S.; Lu, J.; Mushkudiani, N.A.; Maas, A.I.R.; Marmarou, A.; Steyerberg, E.W. Multivariable prognostic analysis in traumatic brain injury: Results from the IMPACT study. J. Neurotrauma 2007, 24, 329-337. [CrossRef]

4. $\quad$ Narayan, R.K.; Maas, A.I.R.; Servadei, F.; Skolnick, B.E.; Tillinger, M.N.; Marshall, L.F.; Traumatic Intracerebral Hemorrhage Study Group. Progression of traumatic intracerebral hemorrhage: A prospective observational study. J. Neurotrauma 2008, 25, 629-639. [CrossRef]

5. O'Phelan, K.H.; Park, D.; Efird, J.T.; Johnson, K.; Albano, M.; Beniga, J.; Green, D.M.; Chang, C.W.J. Patterns of increased intracranial pressure after severe traumatic brain injury. Neurocrit. Care 2009, 10, 280-286. [CrossRef]

6. Kurland, D.; Hong, C.; Aarabi, B.; Gerzanich, V.; Simard, J.M. Hemorrhagic progression of a contusion after traumatic brain injury: A review. J. Neurotrauma 2012, 29, 19-31. [CrossRef] [PubMed]

7. Oertel, M.; Kelly, D.F.; McArthur, D.; Boscardin, W.J.; Glenn, T.C.; Lee, J.H.; Gravori, T.; Obukhov, D.; McBride, D.Q.; Martin, N.A. Progressive hemorrhage after head trauma: Predictors and consequences of the evolving injury. J. Neurosurg. 2002, 96, 109-116. [CrossRef] [PubMed]

8. Chang, E.F.; Meeker, M.; Holland, M.C. Acute traumatic intraparenchymal hemorrhage: Risk factors for progression in the early post-injury period. Neurosurgery 2006, 58, 647-656. [CrossRef]

9. Tong, W.-S.; Zheng, P.; Xu, J.-F.; Guo, Y.-J.; Zeng, J.-S.; Yang, W.-J.; Li, G.-Y.; He, B.; Yu, H. Early CT signs of progressive hemorrhagic injury following acute traumatic brain injury. Neuroradiology 2011, 53, 305-309. [CrossRef] [PubMed]

10. Juratli, T.A.; Zang, B.; Litz, R.J.; Sitoci, K.-H.; Aschenbrenner, U.; Gottschlich, B.; Daubner, D.; Schackert, G.; Sobottka, S.B. Early hemorrhagic progression of traumatic brain contusions: Frequency, correlation with coagulation disorders, and patient outcome: A prospective study. J. Neurotrauma 2014, 31, 1521-1527. [CrossRef] [PubMed]

11. Carnevale, J.A.; Segar, D.J.; Powers, A.Y.; Shah, M.; Doberstein, C.; Drapcho, B.; Morrison, J.F.; Williams, J.R.; Collins, S.; Monteiro, K.; et al. Blossoming contusions: Identifying factors contributing to the expansion of traumatic intracerebral hemorrhage. J. Neurosurg. 2018, 129, 1305-1316. [CrossRef] [PubMed]

12. Yuan, F.; Ding, J.; Chen, H.; Guo, Y.; Wang, G.; Gao, W.-W.; Chen, S.-W.; Tian, H.-L. Predicting progressive hemorrhagic injury after traumatic brain injury: Derivation and validation of a risk score based on admission characteristics. J. Neurotrauma 2012, 29, 2137-2142. [CrossRef] [PubMed] 
13. Eisenberg, H.M.; Gary, H.E.; Aldrich, E.F.; Saydjari, C.; Turner, B.; Foulkes, M.A.; Jane, J.A.; Marmarou, A.; Marshall, L.F.; Young, H.F. Initial CT findings in 753 patients with severe head injury. A report from the NIH Traumatic Coma Data Bank. J. Neurosurg. 1990, 73, 688-698. [CrossRef] [PubMed]

14. Jha, R.M.; Kochanek, P.M. A precision medicine approach to cerebral edema and intracranial hypertension after severe traumatic brain injury: Quo vadis? Curr. Neurol. Neurosci. Rep. 2018, 18, 105. [CrossRef] [PubMed]

15. Jha, R.M.; Kochanek, P.M.; Simard, J.M. Pathophysiology and treatment of cerebral edema in traumatic brain injury. Neuropharmacology 2019, 145, 230-246. [CrossRef] [PubMed]

16. Carney, N.; Totten, A.M.; O’Reilly, C.; Ullman, J.S.; Hawryluk, G.W.J.; Bell, M.J.; Bratton, S.L.; Chesnut, R.; Harris, O.A.; Kissoon, N.; et al. Guidelines for the management of severe traumatic brain injury, fourth edition. Neurosurgery 2017, 80, 6-15. [CrossRef]

17. Chesnut, R.M.; Marshall, L.F.; Klauber, M.R.; Blunt, B.A.; Baldwin, N.; Eisenberg, H.M.; Jane, J.A.; Marmarou, A.; Foulkes, M.A. The role of secondary brain injury in determining outcome from severe head injury. J. Trauma 1993, 34, 216-222. [CrossRef]

18. Feickert, H.J.; Drommer, S.; Heyer, R. Severe head injury in children: Impact of risk factors on outcome. J. Trauma 1999, 47, 33-38. [CrossRef]

19. Feldmann, H.; Klages, G.; Gärtner, F.; Scharfenberg, J. The prognostic value of intracranial pressure monitoring after severe head injuries. In Proceedings of the 6th European Congress of Neurosurgery; Acta Neurochirurgica Book Series Volume 28; Brihaye, J., Clarke, P.R.R., Loew, F., Overgaard, J., Pásztor, E., Pertuiset, B., Schürmann, K., Symon, L., Eds.; Springer: Vienna, Austria, 1979; pp. 74-77.

20. Hudak, A.M.; Peng, L.; Marquez de la Plata, C.; Thottakara, J.; Moore, C.; Harper, C.; McColl, R.; Babcock, E.; Diaz-Arrastia, R. Cytotoxic and vasogenic cerebral oedema in traumatic brain injury: Assessment with FLAIR and DWI imaging. Brain Inj. 2014, 28, 1602-1609. [CrossRef] [PubMed]

21. Iaccarino, C.; Schiavi, P.; Picetti, E.; Goldoni, M.; Cerasti, D.; Caspani, M.; Servadei, F. Patients with brain contusions: Predictors of outcome and relationship between radiological and clinical evolution. J. Neurosurg. 2014, 120, 908-918. [CrossRef]

22. Marmarou, A.; Anderson, R.L.; Ward, J.D.; Choi, S.C.; Young, H.F.; Eisenberg, H.M.; Foulkes, M.A.; Marshall, L.F.; Jane, J.A. Impact of ICP instability and hypotension on outcome in patients with severe head trauma. J. Neurosurg. 1991, 75, S59-S66. [CrossRef]

23. Marshall, L.F.; Smith, R.W.; Shapiro, H.M. The outcome with aggressive treatment in severe head injuries. Part I: The significance of intracranial pressure monitoring. J. Neurosurg. 1979, 50, 20-25. [CrossRef] [PubMed]

24. Miller, J.D.; Becker, D.P.; Ward, J.D.; Sullivan, H.G.; Adams, W.E.; Rosner, M.J. Significance of intracranial hypertension in severe head injury. J. Neurosurg. 1977, 47, 503-516. [CrossRef]

25. Saul, T.G.; Ducker, T.B. Effect of intracranial pressure monitoring and aggressive treatment on mortality in severe head injury. J. Neurosurg. 1982, 56, 498-503. [CrossRef]

26. Stocchetti, N.; Zanaboni, C.; Colombo, A.; Citerio, G.; Beretta, L.; Ghisoni, L.; Zanier, E.R.; Canavesi, K. Refractory intracranial hypertension and "second-tier" therapies in traumatic brain injury. Intensive Care Med. 2008, 34, 461-467. [CrossRef] [PubMed]

27. Tucker, B.; Aston, J.; Dines, M.; Caraman, E.; Yacyshyn, M.; McCarthy, M.; Olson, J.E. Early brain edema is a predictor of in-hospital mortality in traumatic brain injury. J. Emerg. Med. 2017, 53, 18-29. [CrossRef]

28. Jha, R.M.; Elmer, J.; Zusman, B.E.; Desai, S.; Puccio, A.M.; Okonkwo, D.O.; Park, S.Y.; Shutter, L.A.; Wallisch, J.S.; Conley, Y.P.; et al. Intracranial pressure trajectories: A novel approach to informing severe traumatic brain injury phenotypes. Crit. Care Med. 2018, 46, 1792-1802. [CrossRef] [PubMed]

29. Griffin, A.D.; Turtzo, L.C.; Parikh, G.Y.; Tolpygo, A.; Lodato, Z.; Moses, A.D.; Nair, G.; Perl, D.P.; Edwards, N.A.; Dardzinski, B.J.; et al. Traumatic microbleeds suggest vascular injury and predict disability in traumatic brain injury. Brain 2019, 142, 3550-3564. [CrossRef]

30. Izzy, S.; Mazwi, N.L.; Martinez, S.; Spencer, C.A.; Klein, J.P.; Parikh, G.; Glenn, M.B.; Greenberg, S.M.; Greer, D.M.; Wu, O.; et al. Revisiting grade 3 diffuse axonal injury: Not all brainstem microbleeds are prognostically equal. Neurocrit. Care 2017, 27, 199-207. [CrossRef]

31. Yuh, E.L.; Mukherjee, P.; Lingsma, H.F.; Yue, J.K.; Ferguson, A.R.; Gordon, W.A.; Valadka, A.B.; Schnyer, D.M.; Okonkwo, D.O.; Maas, A.I.R.; et al. TRACK-TBI investigators magnetic resonance imaging improves 3-month outcome prediction in mild traumatic brain injury. Ann. Neurol. 2013, 73, 224-235. [CrossRef] 
32. Beauchamp, M.H.; Beare, R.; Ditchfield, M.; Coleman, L.; Babl, F.E.; Kean, M.; Crossley, L.; Catroppa, C.; Yeates, K.O.; Anderson, V. Susceptibility weighted imaging and its relationship to outcome after pediatric traumatic brain injury. Cortex 2013, 49, 591-598. [CrossRef] [PubMed]

33. Narayan, R.K.; Kishore, P.R.; Becker, D.P.; Ward, J.D.; Enas, G.G.; Greenberg, R.P.; Domingues Da Silva, A.; Lipper, M.H.; Choi, S.C.; Mayhall, C.G.; et al. Intracranial pressure: To monitor or not to monitor? A review of our experience with severe head injury. J. Neurosurg. 1982, 56, 650-659. [CrossRef] [PubMed]

34. Nelson, D.W.; Nyström, H.; MacCallum, R.M.; Thornquist, B.; Lilja, A.; Bellander, B.-M.; Rudehill, A.; Wanecek, M.; Weitzberg, E. Extended analysis of early computed tomography scans of traumatic brain injured patients and relations to outcome. J. Neurotrauma 2010, 27, 51-64. [CrossRef] [PubMed]

35. Maas, A.I.R.; Steyerberg, E.W.; Butcher, I.; Dammers, R.; Lu, J.; Marmarou, A.; Mushkudiani, N.A.; McHugh, G.S.; Murray, G.D. Prognostic value of computerized tomography scan characteristics in traumatic brain injury: Results from the IMPACT study. J. Neurotrauma 2007, 24, 303-314. [CrossRef] [PubMed]

36. Pergakis, M.; Badjatia, N.; Chaturvedi, S.; Cronin, C.A.; Kimberly, W.T.; Sheth, K.N.; Simard, J.M. BIIB093 (IV glibenclamide): An investigational compound for the prevention and treatment of severe cerebral edema. Expert Opin. Investig. Drugs 2019, 28, 1-10. [CrossRef]

37. Jha, R.M.; Kochanek, P.M.; Simard, J.M. Central nervous system trauma: Pharmacological and therapeutic approaches. In Encyclopedia of Molecular Cell Biology-Molecular Pharmacology; in press.

38. Donkin, J.J.; Vink, R. Mechanisms of cerebral edema in traumatic brain injury: Therapeutic developments. Curr. Opin. Neurol. 2010, 23, 293-299. [CrossRef]

39. Hawryluk, G.W.J.; Aguilera, S.; Buki, A.; Bulger, E.; Citerio, G.; Cooper, D.J.; Arrastia, R.D.; Diringer, M.; Figaji, A.; Gao, G.; et al. A management algorithm for patients with intracranial pressure monitoring: The Seattle International Severe Traumatic Brain Injury Consensus Conference (SIBICC). Intensive Care Med. 2019. [CrossRef]

40. Hutchinson, P.J.; Kolias, A.G.; Timofeev, I.S.; Corteen, E.A.; Czosnyka, M.; Timothy, J.; Anderson, I.; Bulters, D.O.; Belli, A.; Eynon, C.A.; et al. RESCUEicp trial collaborators trial of decompressive craniectomy for traumatic intracranial hypertension. N. Engl. J. Med. 2016, 375, 1119-1130. [CrossRef]

41. Shutter, L.A.; Timmons, S.D. Intracranial pressure rescued by decompressive surgery after traumatic brain injury. N. Engl. J. Med. 2016, 375, 1183-1184. [CrossRef]

42. Cooper, D.J.; Rosenfeld, J.V.; Murray, L.; Arabi, Y.M.; Davies, A.R.; D’Urso, P.; Kossmann, T.; Ponsford, J.; Seppelt, I.; Reilly, P.; et al. DECRA trial investigators; Australian and New Zealand intensive care society clinical trials group decompressive craniectomy in diffuse traumatic brain injury. N. Engl. J. Med. 2011, 364, 1493-1502. [CrossRef]

43. Andrews, P.J.D.; Sinclair, H.L.; Rodriguez, A.; Harris, B.A.; Battison, C.G.; Rhodes, J.K.J.; Murray, G.D.; Eurotherm 3235 Trial Collaborators. Hypothermia for intracranial hypertension after traumatic brain injury. N. Engl. J. Med. 2015, 373, 2403-2412. [CrossRef]

44. CRASH-3 trial collaborators. Effects of tranexamic acid on death, disability, vascular occlusive events and other morbidities in patients with acute traumatic brain injury (CRASH-3): A randomised, placebo-controlled trial. Lancet 2019, 394, 1713-1723. [CrossRef]

45. Weng, S.; Wang, W.; Wei, Q.; Lan, H.; Su, J.; Xu, Y. Effect of tranexamic acid in patients with traumatic brain injury: A systematic review and meta-analysis. World Neurosurg. 2019, 123, 128-135. [CrossRef] [PubMed]

46. Simard, J.M.; Woo, S.K.; Schwartzbauer, G.T.; Gerzanich, V. Sulfonylurea receptor 1 in central nervous system injury: A focused review. J. Cereb. Blood Flow Metab. 2012, 32, 1699-1717. [CrossRef] [PubMed]

47. Aittoniemi, J.; Fotinou, C.; Craig, T.J.; de Wet, H.; Proks, P.; Ashcroft, F.M. Review. SUR1: A unique ATP-binding cassette protein that functions as an ion channel regulator. Philos. Trans. R. Soc. Lond. B Biol. Sci. 2009, 364, 257-267. [CrossRef] [PubMed]

48. Proks, P.; Reimann, F.; Green, N.; Gribble, F.; Ashcroft, F. Sulfonylurea stimulation of insulin secretion. Diabetes 2002, 51, S368-S376. [CrossRef]

49. Haider, S.; Antcliff, J.F.; Proks, P.; Sansom, M.S.P.; Ashcroft, F.M. Focus on Kir6.2: A key component of the ATP-sensitive potassium channel. J. Mol. Cell Cardiol. 2005, 38, 927-936. [CrossRef]

50. Gerzanich, V.; Stokum, J.A.; Ivanova, S.; Woo, S.K.; Tsymbalyuk, O.; Sharma, A.; Akkentli, F.; Imran, Z.; Aarabi, B.; Sahuquillo, J.; et al. Sulfonylurea receptor 1, transient receptor potential cation channel subfamily M member 4, and Kir6.2: Role in hemorrhagic progression of contusion. J. Neurotrauma 2019, 36, 1060-1079. [CrossRef] 
51. Castro, L.; Noelia, M.; Vidal-Jorge, M.; Sánchez-Ortiz, D.; Gándara, D.; Martínez-Saez, E.; Cicuéndez, M.; Poca, M.-A.; Simard, J.M.; Sahuquillo, J. Kir6.2, the pore-forming subunit of ATP-sensitive $\mathrm{K}^{+}$channels, is overexpressed in human posttraumatic brain contusions. J. Neurotrauma 2018, 36. [CrossRef]

52. Chen, M.; Simard, J.M. Cell swelling and a nonselective cation channel regulated by internal $\mathrm{Ca}^{2+}$ and ATP in native reactive astrocytes from adult rat brain. J. Neurosci. 2001, 21, 6512-6521. [CrossRef]

53. Chen, M.; Dong, Y.; Simard, J.M. Functional coupling between sulfonylurea receptor type 1 and a nonselective cation channel in reactive astrocytes from adult rat brain. J. Neurosci. 2003, 23, 8568-8577. [CrossRef] [PubMed]

54. Woo, S.K.; Kwon, M.S.; Ivanov, A.; Gerzanich, V.; Simard, J.M. The sulfonylurea receptor 1 (SUR1)-transient receptor potential melastatin 4 (TRPM4) channel. J. Biol. Chem. 2013, 288, 3655-3667. [CrossRef] [PubMed]

55. Stokum, J.A.; Kwon, M.S.; Woo, S.K.; Tsymbalyuk, O.; Vennekens, R.; Gerzanich, V.; Simard, J.M. SUR1-TRPM4 and AQP4 form a heteromultimeric complex that amplifies ion/water osmotic coupling and drives astrocyte swelling. Glia 2018, 66, 108-125. [CrossRef] [PubMed]

56. Simard, J.M.; Chen, M.; Tarasov, K.V.; Bhatta, S.; Ivanova, S.; Melnitchenko, L.; Tsymbalyuk, N.; West, G.A.; Gerzanich, V. Newly expressed SUR1-regulated NC(Ca-ATP) channel mediates cerebral edema after ischemic stroke. Nat. Med. 2006, 12, 433-440. [CrossRef]

57. Simard, J.M.; Woo, S.K.; Tsymbalyuk, N.; Voloshyn, O.; Yurovsky, V.; Ivanova, S.; Lee, R.; Gerzanich, V. Glibenclamide-10-h treatment window in a clinically relevant model of stroke. Transl. Stroke Res. 2012, 3, 286-295. [CrossRef]

58. Mehta, R.I.; Tosun, C.; Ivanova, S.; Tsymbalyuk, N.; Famakin, B.M.; Kwon, M.S.; Castellani, R.J.; Gerzanich, V.; Simard, J.M. SUR1-TRPM4 cation channel expression in human cerebral infarcts. J. Neuropathol. Exp. Neurol. 2015, 74, 835-849. [CrossRef]

59. Mehta, R.I.; Ivanova, S.; Tosun, C.; Castellani, R.J.; Gerzanich, V.; Simard, J.M. Sulfonylurea receptor 1 expression in human cerebral infarcts. J. Neuropathol. Exp. Neurol. 2013, 72, 871-883. [CrossRef]

60. Patel, A.D.; Gerzanich, V.; Geng, Z.; Simard, J.M. Glibenclamide reduces hippocampal injury and preserves rapid spatial learning in a model of traumatic brain injury. J. Neuropathol. Exp. Neurol. 2010, 69, 1177-1190. [CrossRef]

61. Simard, J.M.; Kilbourne, M.; Tsymbalyuk, O.; Tosun, C.; Caridi, J.; Ivanova, S.; Keledjian, K.; Bochicchio, G.; Gerzanich, V. Key role of sulfonylurea receptor 1 in progressive secondary hemorrhage after brain contusion. J. Neurotrauma 2009, 26, 2257-2267. [CrossRef]

62. Martínez-Valverde, T.; Vidal-Jorge, M.; Martínez-Saez, E.; Castro, L.; Arikan, F.; Cordero, E.; Rădoi, A.; Poca, M.-A.; Simard, J.M.; Sahuquillo, J. Sulfonylurea receptor 1 in humans with post-traumatic brain contusions. J. Neurotrauma 2015, 32, 1478-1487. [CrossRef]

63. Simard, J.M.; Tsymbalyuk, O.; Ivanov, A.; Ivanova, S.; Bhatta, S.; Geng, Z.; Woo, S.K.; Gerzanich, V. Endothelial sulfonylurea receptor 1-regulated NC Ca-ATP channels mediate progressive hemorrhagic necrosis following spinal cord injury. J. Clin. Investig. 2007, 117, 2105-2113. [CrossRef] [PubMed]

64. Simard, J.M.; Woo, S.K.; Norenberg, M.D.; Tosun, C.; Chen, Z.; Ivanova, S.; Tsymbalyuk, O.; Bryan, J.; Landsman, D.; Gerzanich, V. Brief suppression of $A b c c 8$ prevents autodestruction of spinal cord after trauma. Sci. Transl. Med. 2010, 2, 28ra29. [CrossRef] [PubMed]

65. Jiang, B.; Li, L.; Chen, Q.; Tao, Y.; Yang, L.; Zhang, B.; Zhang, J.H.; Feng, H.; Chen, Z.; Tang, J.; et al. Role of glibenclamide in brain injury after intracerebral hemorrhage. Transl. Stroke Res. 2017, 8, 183-193. [CrossRef] [PubMed]

66. Tosun, C.; Kurland, D.B.; Mehta, R.; Castellani, R.J.; deJong, J.L.; Kwon, M.S.; Woo, S.K.; Gerzanich, V.; Simard, J.M. Inhibition of the SUR1-TRPM4 channel reduces neuroinflammation and cognitive impairment in subarachnoid hemorrhage. Stroke 2013, 44, 3522-3528. [CrossRef]

67. Simard, J.M.; Geng, Z.; Woo, S.K.; Ivanova, S.; Tosun, C.; Melnichenko, L.; Gerzanich, V. Glibenclamide reduces inflammation, vasogenic edema, and caspase-3 activation after subarachnoid hemorrhage. J. Cereb. Blood Flow Metab. 2009, 29, 317-330. [CrossRef]

68. Thompson, E.M.; Pishko, G.L.; Muldoon, L.L.; Neuwelt, E.A. Inhibition of SUR1 decreases the vascular permeability of cerebral metastases. Neoplasia 2013, 15, 535-543. [CrossRef]

69. Huang, K.; Gu, Y.; Hu, Y.; Ji, Z.; Wang, S.; Lin, Z.; Li, X.; Xie, Z.; Pan, S. Glibenclamide improves survival and neurologic outcome after cardiac arrest in rats. Crit. Care Med. 2015, 43, e341-e349. [CrossRef] 
70. Huang, K.; Wang, Z.; Gu, Y.; Hu, Y.; Ji, Z.; Wang, S.; Lin, Z.; Li, X.; Xie, Z.; Pan, S. Glibenclamide is comparable to target temperature management in improving survival and neurological outcome after asphyxial cardiac arrest in rats. J. Am. Heart Assoc. 2016, 5, e003465. [CrossRef]

71. Jayakumar, A.R.; Valdes, V.; Tong, X.Y.; Shamaladevi, N.; Gonzalez, W.; Norenberg, M.D. Sulfonylurea receptor 1 contributes to the astrocyte swelling and brain edema in acute liver failure. Transl. Stroke Res. 2014, 5, 28-37. [CrossRef]

72. Makar, T.K.; Gerzanich, V.; Nimmagadda, V.K.C.; Jain, R.; Lam, K.; Mubariz, F.; Trisler, D.; Ivanova, S.; Woo, S.K.; Kwon, M.S.; et al. Silencing of $A b c c 8$ or inhibition of newly upregulated SUR1-TRPM4 reduce inflammation and disease progression in experimental autoimmune encephalomyelitis. J. Neuroinflammation 2015, 12, 210. [CrossRef]

73. Gerzanich, V.; Makar, T.K.; Guda, P.R.; Kwon, M.S.; Stokum, J.A.; Woo, S.K.; Ivanova, S.; Ivanov, A.; Mehta, R.I.; Morris, A.B.; et al. Salutary effects of glibenclamide during the chronic phase of murine experimental autoimmune encephalomyelitis. J. Neuroinflammation 2017, 14, 177. [CrossRef] [PubMed]

74. Schattling, B.; Steinbach, K.; Thies, E.; Kruse, M.; Menigoz, A.; Ufer, F.; Flockerzi, V.; Brück, W.; Pongs, O.; Vennekens, R.; et al. TRPM4 cation channel mediates axonal and neuronal degeneration in experimental autoimmune encephalomyelitis and multiple sclerosis. Nat. Med. 2012, 18, 1805-1811. [CrossRef] [PubMed]

75. Stokum, J.A.; Gerzanich, V.; Simard, J.M. Molecular pathophysiology of cerebral edema. J. Cereb. Blood Flow Metab. 2016, 36, 513-538. [CrossRef] [PubMed]

76. Simard, J.M.; Kent, T.A.; Chen, M.; Tarasov, K.V.; Gerzanich, V. Brain oedema in focal ischaemia: Molecular pathophysiology and theoretical implications. Lancet Neurol. 2007, 6, 258-268. [CrossRef]

77. Hosier, H.; Peterson, D.; Tsymbalyuk, O.; Keledjian, K.; Smith, B.R.; Ivanova, S.; Gerzanich, V.; Popovich, P.G.; Simard, J.M. A direct comparison of three clinically relevant treatments in a rat model of cervical spinal cord injury. J. Neurotrauma 2015, 32, 1633-1644. [CrossRef]

78. Simard, J.M.; Tsymbalyuk, N.; Tsymbalyuk, O.; Ivanova, S.; Yurovsky, V.; Gerzanich, V. Glibenclamide is superior to decompressive craniectomy in a rat model of malignant stroke. Stroke 2010, 41, 531-537. [CrossRef]

79. Wali, B.; Ishrat, T.; Atif, F.; Hua, F.; Stein, D.G.; Sayeed, I. Glibenclamide administration attenuates infarct volume, hemispheric swelling, and functional impairments following permanent focal cerebral ischemia in rats. Stroke Res. Treat. 2012, 2012, 460909. [CrossRef]

80. Huang, K.; Wang, Z.; Gu, Y.; Ji, Z.; Lin, Z.; Wang, S.; Pan, S.; Wu, Y. Glibenclamide prevents water diffusion abnormality in the brain after cardiac arrest in rats. Neurocrit. Care 2018, 29, 128-135. [CrossRef]

81. Nakayama, S.; Taguchi, N.; Isaka, Y.; Nakamura, T.; Tanaka, M. Glibenclamide and therapeutic hypothermia have comparable effect on attenuating global cerebral edema following experimental cardiac arrest. Neurocrit. Care 2018, 29, 119-127. [CrossRef]

82. Zweckberger, K.; Hackenberg, K.; Jung, C.S.; Hertle, D.N.; Kiening, K.L.; Unterberg, A.W.; Sakowitz, O.W. Glibenclamide reduces secondary brain damage after experimental traumatic brain injury. Neuroscience 2014, 272, 199-206. [CrossRef]

83. Xu, Z.-M.; Yuan, F.; Liu, Y.-L.; Ding, J.; Tian, H.-L. Glibenclamide attenuates blood-brain barrier disruption in adult mice after traumatic brain injury. J. Neurotrauma 2017, 34, 925-933. [CrossRef]

84. Jha, R.M.; Molyneaux, B.J.; Jackson, T.C.; Wallisch, J.S.; Park, S.-Y.; Poloyac, S.; Vagni, V.A.; Janesko-Feldman, K.L.; Hoshitsuki, K.; Minnigh, M.B.; et al. Glibenclamide produces region-dependent effects on cerebral edema in a combined injury model of traumatic brain injury and hemorrhagic shock in mice. J. Neurotrauma 2018, 35, 2125-2135. [CrossRef] [PubMed]

85. Jha, R.; Yan, H.; Dixon, C.E.; Poloyac, S.; Jackson, T.; Hoshitsuki, K.; Ma, X.; Henchir, J.; Janesko-Feldman, K.; Kochanek, P. Evaluation of glibenclamide in the Pittsburgh controlled cortical impact model of traumatic brain injury: An OBTT consortium study. J. Neurotrauma 2015, 32, 119.

86. Simard, J.M.; Tsymbalyuk, O.; Keledjian, K.; Ivanov, A.; Ivanova, S.; Gerzanich, V. Comparative effects of glibenclamide and riluzole in a rat model of severe cervical spinal cord injury. Exp. Neurol. 2012, 233, 566-574. [CrossRef] [PubMed]

87. Simard, J.M.; Popovich, P.G.; Tsymbalyuk, O.; Gerzanich, V. Spinal cord injury with unilateral versus bilateral primary hemorrhage-Effects of glibenclamide. Exp. Neurol. 2012, 233, 829-835. [CrossRef] 
88. Popovich, P.G.; Lemeshow, S.; Gensel, J.C.; Tovar, C.A. Independent evaluation of the effects of glibenclamide on reducing progressive hemorrhagic necrosis after cervical spinal cord injury. Exp. Neurol. 2012, 233, 615-622. [CrossRef] [PubMed]

89. Simard, J.M.; Sheth, K.N.; Kimberly, W.T.; Stern, B.J.; del Zoppo, G.J.; Jacobson, S.; Gerzanich, V. Glibenclamide in cerebral ischemia and stroke. Neurocrit. Care 2014, 20,319-333. [CrossRef]

90. Nedergaard, M.; Kraig, R.P.; Tanabe, J.; Pulsinelli, W.A. Dynamics of interstitial and intracellular $\mathrm{pH}$ in evolving brain infarct. Am. J. Physiol. 1991, 260, R581-R588. [CrossRef]

91. Sheth, K.N.; Elm, J.J.; Molyneaux, B.J.; Hinson, H.; Beslow, L.A.; Sze, G.K.; Ostwaldt, A.-C.; Del Zoppo, G.J.; Simard, J.M.; Jacobson, S.; et al. Safety and efficacy of intravenous glyburide on brain swelling after large hemispheric infarction (GAMES-RP): A randomised, double-blind, placebo-controlled phase 2 trial. Lancet Neurol. 2016, 15, 1160-1169. [CrossRef]

92. Sheth, K.N.; Kimberly, W.T.; Elm, J.J.; Kent, T.A.; Yoo, A.J.; Thomalla, G.; Campbell, B.; Donnan, G.A.; Davis, S.M.; Albers, G.W.; et al. Exploratory analysis of glyburide as a novel therapy for preventing brain swelling. Neurocrit. Care 2014, 21, 43-51. [CrossRef]

93. Kimberly, W.T.; Battey, T.W.K.; Pham, L.; Wu, O.; Yoo, A.J.; Furie, K.L.; Singhal, A.B.; Elm, J.J.; Stern, B.J.; Sheth, K.N. Glyburide is associated with attenuated vasogenic edema in stroke patients. Neurocrit. Care 2014, 20, 193-201. [CrossRef] [PubMed]

94. King, Z.A.; Sheth, K.N.; Kimberly, W.T.; Simard, J.M. Profile of intravenous glyburide for the prevention of cerebral edema following large hemispheric infarction: Evidence to date. Drug Des. Devel. Ther. 2018, 12, 2539-2552. [CrossRef]

95. Simard, J.M.; Geng, Z.; Silver, F.L.; Sheth, K.N.; Kimberly, W.T.; Stern, B.J.; Colucci, M.; Gerzanich, V. Does inhibiting SUR1 complement rt-PA in cerebral ischemia? Ann. N. Y. Acad. Sci. 2012, 1268, 95-107. [CrossRef]

96. Simard, J.M.; Yurovsky, V.; Tsymbalyuk, N.; Melnichenko, L.; Ivanova, S.; Gerzanich, V. Protective effect of delayed treatment with low-dose glibenclamide in three models of ischemic stroke. Stroke J. Cereb. Circ. 2009, 40, 604-609. [CrossRef] [PubMed]

97. Woo, S.K.; Kwon, M.S.; Geng, Z.; Chen, Z.; Ivanov, A.; Bhatta, S.; Gerzanich, V.; Simard, J.M. Sequential activation of hypoxia-inducible factor 1 and specificity protein 1 is required for hypoxia-induced transcriptional stimulation of Abcc8. J. Cereb. Blood Flow Metab. 2012, 32, 525-536. [CrossRef] [PubMed]

98. Verstraeten, S.V.; Mackenzie, G.G.; Oteiza, P.I. The plasma membrane plays a central role in cells response to mechanical stress. Biochim. Biophys. Acta 2010, 1798, 1739-1749. [CrossRef] [PubMed]

99. Davis, M.E.; Grumbach, I.M.; Fukai, T.; Cutchins, A.; Harrison, D.G. Shear stress regulates endothelial nitric-oxide synthase promoter activity through nuclear factor kB binding. J. Biol. Chem. 2004, 279, 163-168. [CrossRef] [PubMed]

100. Kurland, D.B.; Gerzanich, V.; Karimy, J.K.; Woo, S.K.; Vennekens, R.; Freichel, M.; Nilius, B.; Bryan, J.; Simard, J.M. The SUR1-TRPM4 channel regulates NOS2 transcription in TLR4-activated microglia. J. Neuroinflam. 2016, 13, 130. [CrossRef]

101. Stokum, J.A.; Keledjian, K.; Hayman, E.; Karimy, J.K.; Pampori, A.; Imran, Z.; Woo, S.K.; Gerzanich, V.; Simard, J.M. Glibenclamide pretreatment protects against chronic memory dysfunction and glial activation in rat cranial blast traumatic brain injury. Behav. Brain Res. 2017, 333, 43-53. [CrossRef]

102. Gerzanich, V.; Kwon, M.S.; Woo, S.K.; Ivanov, A.; Simard, J.M. SUR1-TRPM4 channel activation and phasic secretion of MMP-9 induced by tPA in brain endothelial cells. PLoS ONE 2018, 13, e0195526. [CrossRef]

103. Simon, D.W.; McGeachy, M.J.; Bayır, H.; Clark, R.S.B.; Loane, D.J.; Kochanek, P.M. The far-reaching scope of neuroinflammation after traumatic brain injury. Nat. Rev. Neurol. 2017, 13, 171-191. [CrossRef]

104. Kumar, A.; Chen, S.-H.; Kadiiska, M.B.; Hong, J.-S.; Zielonka, J.; Kalyanaraman, B.; Mason, R.P. Inducible nitric oxide synthase is key to peroxynitrite-mediated, LPS-induced protein radical formation in murine microglial BV2 cells. Free Radic. Biol. Med. 2014, 73, 51-59. [CrossRef] [PubMed]

105. Béchade, C.; Colasse, S.; Diana, M.A.; Rouault, M.; Bessis, A. NOS2 expression is restricted to neurons in the healthy brain but is triggered in microglia upon inflammation. Glia 2014, 62, 956-963. [CrossRef]

106. Chodobski, A.; Zink, B.J.; Szmydynger-Chodobska, J. Blood-brain barrier pathophysiology in traumatic brain injury. Transl. Stroke Res. 2011, 2, 492-516. [CrossRef]

107. Turner, R.J.; Sharp, F.R. Implications of MMP9 for blood brain barrier disruption and hemorrhagic transformation following ischemic stroke. Front. Cell Neurosci. 2016, 10, 56. [CrossRef] 
108. Romanic, A.M.; White, R.F.; Arleth, A.J.; Ohlstein, E.H.; Barone, F.C. Matrix metalloproteinase expression increases after cerebral focal ischemia in rats: Inhibition of matrix metalloproteinase- 9 reduces infarct size. Stroke 1998, 29, 1020-1030. [CrossRef] [PubMed]

109. Gorse, K.M.; Lantzy, M.K.; Lee, E.D.; Lafrenaye, A.D. Transient receptor potential melastatin 4 induces astrocyte swelling but not death after diffuse traumatic brain injury. J. Neurotrauma 2018, 35, 1694-1704. [CrossRef] [PubMed]

110. Jha, R.M.; Puccio, A.M.; Chou, S.H.-Y.; Chang, C.-C.H.; Wallisch, J.S.; Molyneaux, B.J.; Zusman, B.E.; Shutter, L.A.; Poloyac, S.M.; Janesko-Feldman, K.L.; et al. Sulfonylurea receptor-1: A novel biomarker for cerebral edema in severe traumatic brain injury. Crit. Care Med. 2017, 45, e255-e264. [CrossRef] [PubMed]

111. Wang, K.K.; Yang, Z.; Zhu, T.; Shi, Y.; Rubenstein, R.; Tyndall, J.A.; Manley, G.T. An update on diagnostic and prognostic biomarkers for traumatic brain injury. Expert Rev. Mol. Diagn. 2018, 18, 165-180. [CrossRef]

112. Brophy, G.M.; Mondello, S.; Papa, L.; Robicsek, S.A.; Gabrielli, A.; Tepas, J.; Buki, A.; Robertson, C.; Tortella, F.C.; Hayes, R.L.; et al. Biokinetic analysis of ubiquitin C-terminal hydrolase-L1 (UCH-L1) in severe traumatic brain injury patient biofluids. J. Neurotrauma 2011, 28, 861-870. [CrossRef]

113. Roberts, D.J.; Jenne, C.N.; Léger, C.; Kramer, A.H.; Gallagher, C.N.; Todd, S.; Parney, I.F.; Doig, C.J.; Yong, V.W.; Kubes, P.; et al. A prospective evaluation of the temporal matrix metalloproteinase response after severe traumatic brain injury in humans. J. Neurotrauma 2013, 30, 1717-1726. [CrossRef] [PubMed]

114. Guilfoyle, M.R.; Carpenter, K.L.H.; Helmy, A.; Pickard, J.D.; Menon, D.K.; Hutchinson, P.J.A. Matrix metalloproteinase expression in contusional traumatic brain injury: A paired microdialysis study. J. Neurotrauma 2015, 32, 1553-1559. [CrossRef] [PubMed]

115. Zeiler, F.A.; McFadyen, C.; Newcombe, V.F.J.; Synnot, A.; Donoghue, E.L.; Ripatti, S.; Steyerberg, E.W.; Gruen, R.L.; McAllister, T.W.; Rosand, J.; et al. Genetic influences on patient-oriented outcomes in traumatic brain injury: A living systematic review of non-apolipoprotein E single-nucleotide polymorphisms. J. Neurotrauma 2019. [CrossRef] [PubMed]

116. Zeiler, F.A.; Thelin, E.P.; Donnelly, J.; Stevens, A.R.; Smielewski, P.; Czosnyka, M.; Hutchinson, P.J.; Menon, D.K. Genetic drivers of cerebral blood flow dysfunction in TBI: A speculative synthesis. Nat. Rev. Neurol. 2019, 15, 25-39. [CrossRef]

117. McFadyen, C.A.; Zeiler, F.A.; Newcombe, V.; Synnot, A.; Steyerberg, E.; Gruen, R.L.; Rosand, J.; Palotie, A.; Maas, A.I.R.; Menon, D.K. Apolipoprotein E4 polymorphism and outcomes from traumatic brain injury: A living systematic review and meta-analysis. J. Neurotrauma 2019. [CrossRef]

118. Yue, J.K.; Pronger, A.M.; Ferguson, A.R.; Temkin, N.R.; Sharma, S.; Rosand, J.; Sorani, M.D.; McAllister, T.W.; Barber, J.; Winkler, E.A.; et al. COBRIT investigators; TRACK-TBI investigators association of a common genetic variant within ANKK1 with six-month cognitive performance after traumatic brain injury. Neurogenetics 2015, 16, 169-180. [CrossRef]

119. Winkler, E.A.; Yue, J.K.; Ferguson, A.R.; Temkin, N.R.; Stein, M.B.; Barber, J.; Yuh, E.L.; Sharma, S.; Satris, G.G.; McAllister, T.W.; et al. TRACK-TBI investigators COMT Val ${ }^{158}$ Met polymorphism is associated with post-traumatic stress disorder and functional outcome following mild traumatic brain injury. J. Clin. Neurosci. 2017, 35, 109-116. [CrossRef]

120. Winkler, E.A.; Yue, J.K.; McAllister, T.W.; Temkin, N.R.; Oh, S.S.; Burchard, E.G.; Hu, D.; Ferguson, A.R.; Lingsma, H.F.; Burke, J.F.; et al. TRACK-TBI investigators COMT Val ${ }^{158}$ Met polymorphism is associated with nonverbal cognition following mild traumatic brain injury. Neurogenetics 2016, 17, 31-41. [CrossRef]

121. Yue, J.K.; Robinson, C.K.; Burke, J.F.; Winkler, E.A.; Deng, H.; Cnossen, M.C.; Lingsma, H.F.; Ferguson, A.R.; McAllister, T.W.; Rosand, J.; et al. TRACK-TBI investigators apolipoprotein E epsilon 4 (APOE- $\varepsilon 4$ ) genotype is associated with decreased 6-month verbal memory performance after mild traumatic brain injury. Brain Behav. 2017, 7, e00791. [CrossRef]

122. Jha, R.M.; Puccio, A.M.; Okonkwo, D.O.; Zusman, B.E.; Park, S.-Y.; Wallisch, J.; Empey, P.E.; Shutter, L.A.; Clark, R.S.B.; Kochanek, P.M.; et al. Abcc8 single nucleotide polymorphisms are associated with cerebral edema in severe TBI. Neurocrit. Care 2017, 26, 213-224. [CrossRef]

123. Jha, R.M.; Koleck, T.A.; Puccio, A.M.; Okonkwo, D.O.; Park, S.-Y.; Zusman, B.E.; Clark, R.S.B.; Shutter, L.A.; Wallisch, J.S.; Empey, P.E.; et al. Regionally clustered $A b c c 8$ polymorphisms in a prospective cohort predict cerebral oedema and outcome in severe traumatic brain injury. J. Neurol. Neurosurg. Psychiatry 2018, 89, 1152-1162. [CrossRef] [PubMed] 
124. Jha, R.M.; Desai, S.M.; Zusman, B.E.; Koleck, T.A.; Puccio, A.M.; Okonkwo, D.O.; Park, S.-Y.; Shutter, L.A.; Kochanek, P.M.; Conley, Y.P. Downstream TRPM4 polymorphisms are associated with intracranial hypertension and statistically interact with $A b c c 8$ polymorphisms in a prospective cohort of severe traumatic brain injury. J. Neurotrauma 2019, 36, 1804-1817. [CrossRef] [PubMed]

125. Dardiotis, E.; Paterakis, K.; Tsivgoulis, G.; Tsintou, M.; Hadjigeorgiou, G.F.; Dardioti, M.; Grigoriadis, S.; Simeonidou, C.; Komnos, A.; Kapsalaki, E.; et al. AQP4 tag single nucleotide polymorphisms in patients with traumatic brain injury. J. Neurotrauma 2014, 31, 1920-1926. [CrossRef] [PubMed]

126. Sorani, M.D.; Zador, Z.; Hurowitz, E.; Yan, D.; Giacomini, K.M.; Manley, G.T. Novel variants in human Aquaporin-4 reduce cellular water permeability. Hum. Mol. Genet. 2008, 17, 2379-2389. [CrossRef]

127. Appelboom, G.; Bruce, S.; Duren, A.; Piazza, M.; Monahan, A.; Christophe, B.; Zoller, S.; LoPresti, M.; Connolly, E.S. Aquaporin-4 gene variant independently associated with oedema after intracerebral haemorrhage. Neurol. Res. 2015, 37, 657-661. [CrossRef]

128. Bramlett, H.; Furones-Alonso, O.; Sanchez-Molano, J.; Sequiera, D.; Moreno, W.; Dietrich, W.D. Evaluation of Glibenclamide in the Miami Fluid Percussion Model of Traumatic Brain Injury: An OBTT Consortium Study. Abstracts from the 33rd Annual National Neurotrauma Symposium June 28-July 1, 2015 Santa Fe, New Mexico. J. Neurotrauma 2015, 32. [CrossRef]

129. Jha, R.M.; Koleck, T.; Wu, Y.; Zusman, B.; Salamacha, N.; Wyman, S.; Janesko Feldman, K.; Kochanek, P. Evaluation of Glibenclamide in the Pittsburgh Controlled Cortical Impact Model of Traumatic Brain Injury: An OBTT Consortium Study. Abstracts from the 37th Annual National Neurotrauma Symposium June 29-July 3, 2019 Pittsburgh, Pennsylvania. J. Neurotrauma 2019, 36. [CrossRef]

130. Kochanek, P.M.; Bramlett, H.M.; Dixon, C.E.; Dietrich, W.D.; Mondello, S.; Wang, K.K.W.; Hayes, R.L.; Lafrenaye, A.; Povlishock, J.T.; Tortella, F.C.; et al. Operation brain trauma therapy: 2016 update. Mil. Med. 2018, 183, 303-312. [CrossRef]

131. Kochanek, P.M.; Bramlett, H.M.; Dixon, C.E.; Shear, D.A.; Dietrich, W.D.; Schmid, K.E.; Mondello, S.; Wang, K.K.W.; Hayes, R.L.; Povlishock, J.T.; et al. Approach to modeling, therapy evaluation, drug selection, and biomarker assessments for a multicenter pre-clinical drug screening consortium for acute therapies in severe traumatic brain injury: Operation brain trauma therapy. J. Neurotrauma 2016, 33, 513-522. [CrossRef]

132. Kochanek, P.M.; Bramlett, H.M.; Shear, D.A.; Dixon, C.E.; Mondello, S.; Dietrich, W.D.; Hayes, R.L.; Wang, K.K.W.; Poloyac, S.M.; Empey, P.E.; et al. Synthesis of findings, current investigations, and future directions: Operation brain trauma therapy. J. Neurotrauma 2016, 33, 606-614. [CrossRef]

133. Zafardoost, P.; Ghasemi, A.A.; Salehpour, F.; Piroti, C.; Ziaeii, E. Evaluation of the effect of glibenclamide in patients with diffuse axonal injury due to moderate to severe head trauma. Trauma Mon 2016, 21, e25113. [CrossRef] [PubMed]

134. Khalili, H.; Derakhshan, N.; Niakan, A.; Ghaffarpasand, F.; Salehi, M.; Eshraghian, H.; Shakibafard, A.; Zahabi, B. Effects of oral glibenclamide on brain contusion volume and functional outcome of patients with moderate and severe traumatic brain injuries: A randomized double-blind placebo-controlled clinical trial. World Neurosurg. 2017, 101, 130-136. [CrossRef] [PubMed]

135. Eisenberg, H.M.; Shenton, M.E.; Pasternak, O.; Simard, J.M.; Okonkwo, D.O.; Aldrich, C.; He, F.; Jain, S.; Hayman, E.G. Magnetic resonance imaging pilot study of intravenous glyburide in traumatic brain injury. J. Neurotrauma 2019. [CrossRef] [PubMed]

136. Woo, S.K.; Gerzanich, V.; Simard, J.M. Glibenclamide enhances erythrocyte phagocytosis and resolution of contusion-TBI. J. Neurotrauma. in preparation.

(C) 2020 by the authors. Licensee MDPI, Basel, Switzerland. This article is an open access article distributed under the terms and conditions of the Creative Commons Attribution (CC BY) license (http://creativecommons.org/licenses/by/4.0/). 